\title{
Development of the Circulation Control Flow Scheme used in the NTF Semi-Span FAST-MAC Model
}

\author{
Gregory S. Jones ${ }^{1}$, William E. Milholen, $\mathrm{II}^{2}$, David T. Chan ${ }^{3}$, Brian Allan ${ }^{4}$, Scott L. Goodliff \\ Latunia Melton $^{6}$, Scott G. Anders ${ }^{7}$, Melissa Carter ${ }^{8}$, and Francis Capone ${ }^{9}$ \\ NASA Langley Research Center, Hampton, VA, 23681
}

\begin{abstract}
The application of a circulation control system for high Reynolds numbers was experimentally validated with the Fundamental Aerodynamic Subsonic Transonic Modular Active Control semi-span model in the NASA Langley National Transonic Facility. This model utilized four independent flow paths to modify the lift and thrust performance of a representative advanced transport type of wing. The design of the internal flow paths highlights the challenges associated with high Reynolds number testing in a cryogenic pressurized wind tunnel. Weight flow boundaries for the air delivery system were identified at mildly cryogenic conditions ranging from 0.1 to $10 \mathrm{lbm} / \mathrm{sec}$. Results from the test verified system performance and identified solutions associated with the weight-flow metering system that are linked to internal perforated plates used to achieve flow uniformity at the jet exit.
\end{abstract}

\section{Nomenclature}

\begin{tabular}{|c|c|c|c|}
\hline $\mathrm{A}_{\mathrm{T}}$ & $=$ circulation control throat area $\left(\mathrm{in}^{2}\right)$ & $\mathrm{P}$ & $=$ wind tunnel static pressure $(\mathrm{psi})$ \\
\hline$A_{0}$ & $=$ area of a single orifice $\left(\mathrm{in}^{2}\right)$ & $\operatorname{Re}_{\mathrm{C}}$ & $=$ chord Reynolds number \\
\hline A PLATE & $=$ area of perforated plate without holes $\left(\right.$ in $\left.^{2}\right)$ & $\mathrm{S}$ & $=$ wing plan form area \\
\hline & $=$ wing $\operatorname{span}(\mathrm{in})$ & $s$ & $=$ curvilinear distance along flap chord from exit \\
\hline $\mathrm{b}_{\text {SLOT }}$ & $=$ slot $\operatorname{span}($ in $)$ & SMSS & $=$ Sidewall Model Support System \\
\hline CFD & $=$ Computational Fluid Dynamics & $\mathrm{T}_{0}$ & $=$ wind tunnel total temperature $\left({ }^{\circ} \mathrm{R}\right)$ \\
\hline$C_{p}$ & $=$ pressure coefficient & $\mathrm{T}_{0(\mathrm{JET})}$ & $=$ jet total temperature $\left({ }^{\circ} \mathrm{R}\right)$ \\
\hline $\mathrm{c}$ & $=$ chord $(\mathrm{in})$ & $\mathrm{U}_{\mathrm{JET}}$ & $=$ nozzle throat velocity $(\mathrm{ft} / \mathrm{sec})$ \\
\hline $\mathrm{C}_{\mathrm{DIS}}$ & $=$ nozzle discharge coefficient & $\mathrm{U}_{\mathrm{u}}$ & $=$ upstream perforated plate velocity $\mathrm{ft} / \mathrm{sec}$ ) \\
\hline$d_{o}$ & $=$ perforated plate orifice diameter (in) & $\mathrm{w}_{\mathrm{I}}$ & $=$ ideal weight flow $(\mathrm{lbm} / \mathrm{sec})$ \\
\hline$f$ & $=$ perforated plate open area $(\%$ of total $)$ & $\mathrm{w}_{\mathrm{P}}$ & $=$ measured weight flow $(1 \mathrm{bm} / \mathrm{sec})$ \\
\hline $\mathrm{g}$ & $=$ acceleration due to gravity, $32.17 \mathrm{ft} / \mathrm{sec}^{2}$ & $\rho_{\mathrm{u}}$ & $=$ density upstream of perforated plate $\left(\mathrm{lbm} / \mathrm{ft}^{3}\right)$ \\
\hline $\mathrm{h}$ & $=$ nozzle throat exit height (in) & $\zeta$ & $=$ perforated plate pressure loss coefficient \\
\hline$k_{\mathrm{m}}$ & $=$ perforated plate compressibility factor & $\lambda$ & $=$ friction coefficient \\
\hline $\mathrm{M}_{\infty}$ & $=$ wind tunnel Mach number & $\tau$ & $=$ perforated hole boundary layer growth factor \\
\hline NPR & $=$ nozzle pressure ratio $\left(\mathrm{P}_{0(\mathrm{~J})} / \mathrm{P}\right)$ & & \\
\hline $\mathrm{P}_{0 \text { (PLATE) }}$ & $=$ upstream perforated plate total pressure $(\mathrm{ps}$ & & \\
\hline $\mathrm{P}_{0(\mathrm{~J})}$ & $=$ jet total pressure $(\mathrm{psi})$ & & \\
\hline $\mathrm{P}_{0}$ & $=$ wind tunnel total pressure $(\mathrm{psi})$ & & \\
\hline
\end{tabular}

\footnotetext{
${ }^{1}$ Research Engineer, Flow Physics and Control Branch, Mail Stop 170, AIAA Senior Member

${ }^{2}$ Research Engineer, Configuration Aerodynamics Branch, Mail Stop 499, AIAA Senior Member

${ }^{3}$ Research Engineer, Configuration Aerodynamics Branch, Mail Stop 499, AIAA Senior Member

${ }^{4}$ Research Engineer, Flow Physics and Control Branch, Mail Stop 170, AIAA Senior Member

${ }^{5}$ Test Engineer, Jacobs Technology, Inc., Mail Stop 267, AIAA Senior Member

${ }^{6}$ Research Engineer, Flow Physics and Control Branch, Mail Stop 170, AIAA Associate Fellow

${ }^{7}$ Research Engineer, Revolutionary Aviation Technologies Branch, Mail Stop 207, AIAA Senior Member

${ }^{8}$ Research Engineer, Configuration Aerodynamics Branch, Mail Stop 499, AIAA Senior Member

${ }^{9}$ Research Engineer, AMS, Mail Stop 499, AIAA Senior Member
} 


\section{Introduction}

$\mathrm{M}$ ANY of the advanced aircraft being designed today utilize advanced propulsion and active flow control systems that are often tied to engine and airframe integration. ${ }^{1,2,3,4,5}$ Energy efficiency, community noise, runway independence, and cruise efficiency can no longer be optimized independently because of the close coupling of the engine, airframe, and wing. It has also become more apparent that high lift and cruise trade studies are closely coupled. To evaluate the benefits of these advanced active flow control (AFC) systems one must accurately scale the wing geometry and the propulsive system. Computational Fluid Dynamics (CFD) has become an integral part of the aircraft design process and requires a benchmark data set like the one described below to be a part of the CFD validation process ${ }^{6,7,8,9}$. When applying AFC systems, such as circulation control to scaled models, it is critical that the flow at the intersection of the outer mold line (OML) and the jet exit is representative of the flight vehicle. Since the performance is typically characterized in terms of non-dimensional forces and the jet momentum it is necessary to profile the weight-flow and velocity of the jet. This paper will focus on the internal flow path requirements of the Fundamental Aerodynamic Subsonic Transonic Modular Active Flow (FASTMAC) model. This model utilized an advanced circulation control high lift and cruise system that were recently tested in the NASA Langley National Transonic Facility (NTF) shown in Fig. 1.

The circulation control method that will be discussed throughout this paper introduces momentum directly to the near wall region via a blowing slot, typically located near the wing trailing edge and directed over a simple short-cord flap as shown in Fig. 2. For circulation control applications the flow is typically characterized at the jet exit by jet momentum $(\mathrm{C} \mu)$ or nozzle pressure ratio (NPR) that defines the jet velocity $\left(\mathrm{U}_{\mathrm{JET}}\right)$. The jet momentum is generally related to ideal conditions as shown in Eqn. 1, where internal boundary layer growth is ignored and weight flow is a function of the total pressure measured in the settling chamber of the aft plenum. The jet momentum can also be characterized by using the measured weight flow and the nozzle discharge coefficient as shown in Eqn. 2. The jet velocity used in Eqns. 1 and 2 assumes that the flow expands adiabatically to the free stream static pressure and is characterized by the nozzle pressure ratio (NPR) and jet temperature shown in Eqn. 3. To minimize the uncertainties in measuring these quantities it was determined that NPR, slot height (h), and weight flow $(\mathrm{lbm} / \mathrm{sec})$ are the critical parameters to be measured.

The performance results of the FAST-MAC model are from two test entries described in reference 10 and 11. Fig. 3 highlights issues observed with the model blowing characteristics and defines the boundary for separation control and super-circulation at a $\mathrm{C} \mu \sim 0.03$. While NPR establishes the velocity at the jet exit, it is the momentum coefficient that is best used to collapse the model performance. The uncharacteristic loss of lift performance at a $\mathrm{C} \mu$ of 0.1 (NPR 1.5) for the Mach 0.2 condition resulted in a closer examination of the jet exit blowing characteristics. The remainder of this paper will focus on the internal flow path, jet exit conditions, and jet separation on the flap of the FAST-MAC model.

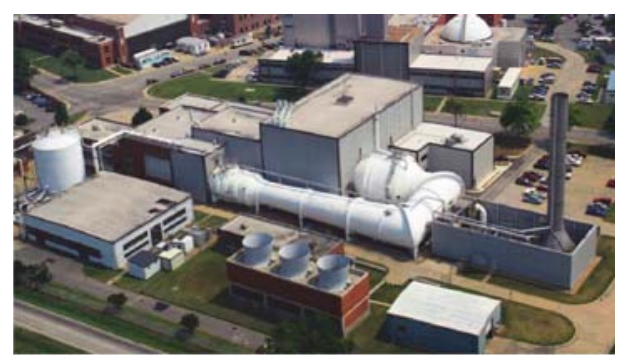

Figure 1. Aerial Photo of NTF

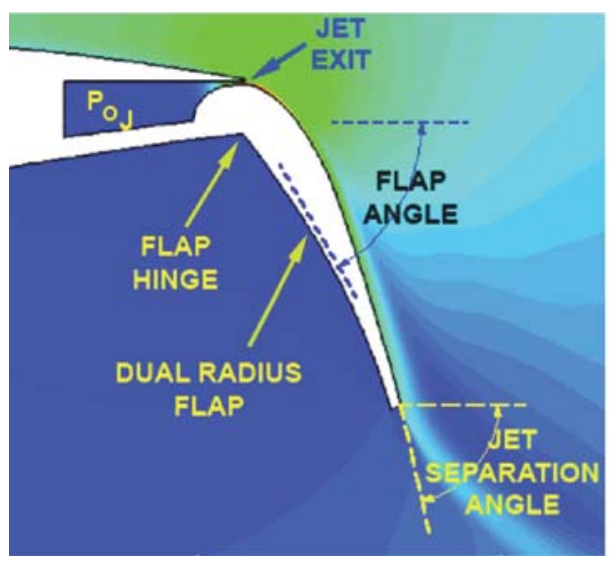

Figure 2. Circulation control blowing slot nomenclature.

$$
\begin{aligned}
& C \mu=\frac{\text { THRUST }}{q_{\infty} S}=\frac{2 h b_{J E T}}{c b} \frac{\rho_{\text {JET }}}{\rho_{\infty}} \frac{U_{\text {JET }}^{2}}{U_{\infty}^{2}} \\
& C \mu=\frac{C_{D I S} w U_{J E T}}{q_{\infty} S} \\
& U_{J E T}=\sqrt{\frac{2 \gamma R\left(T_{o(J E T)}\right)}{\gamma-1}\left[1-\left(\frac{1}{N P R}\right)^{\frac{\gamma-1}{\gamma}}\right]}
\end{aligned}
$$



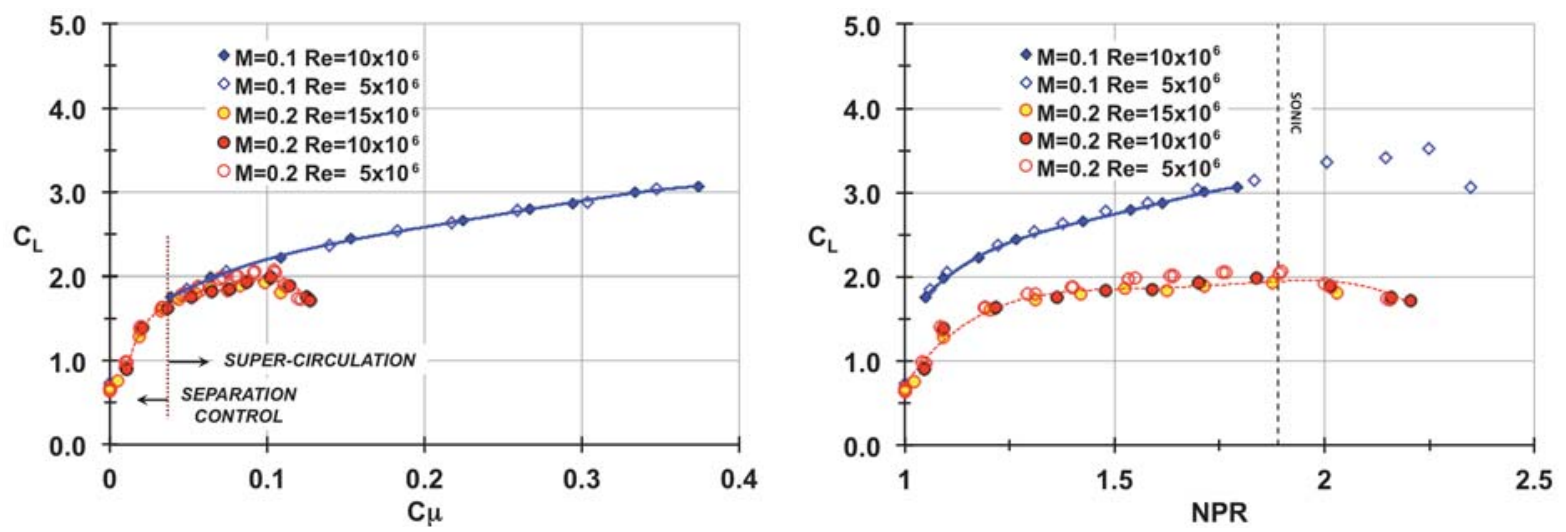

Figure 3. FAST-MAC high lift performance for a $60^{\circ}$ flap angle, $\alpha=0^{\circ}, \mathrm{h} / \mathrm{c}=0.0022$.

\section{Experimental Setup}

\section{A. Wind Tunnel}

The $\operatorname{NTF}^{12}$ (Fig. 4) is one of a limited number of wind tunnel facilities that can achieve flight Reynolds numbers and Mach numbers for transport type aircraft for both cruise and high lift operations. The tunnel is a fan-driven, closed-circuit, continuous-flow, pressurized wind tunnel capable of operating either in dry air at warm temperatures or in nitrogen gas from warm to cryogenic temperatures. The test section is $8.2 \mathrm{ft}$ by $8.2 \mathrm{ft}$ in cross section and $25 \mathrm{ft}$ in length. The test section floor and ceiling are slotted (6 percent open), and the sidewalls are solid. The wind tunnel is capable of an absolute pressure range from 1 atmosphere to 8.3 atmospheres, a temperature range from $-270^{\circ} \mathrm{F}$ to $130^{\circ} \mathrm{F}$, a Mach number range from 0.1 to 1.2 , and a maximum Reynolds number of $146 \times 10^{6}$ per foot at Mach 1. For the blowing test described in this paper the temperature envelope was limited to $-50^{\circ} \mathrm{F}$ to $120^{\circ} \mathrm{F}$ due to limitations in the model protection system.

\section{B. Air Delivery System}

The air delivery system ${ }^{13}$ is a highpressure air system that provides a continuous source of clean, dry air to the test article as shown in Fig. 5. The system was designed to provide a cumulative weight flow of $32 \mathrm{lbm} / \mathrm{sec}$

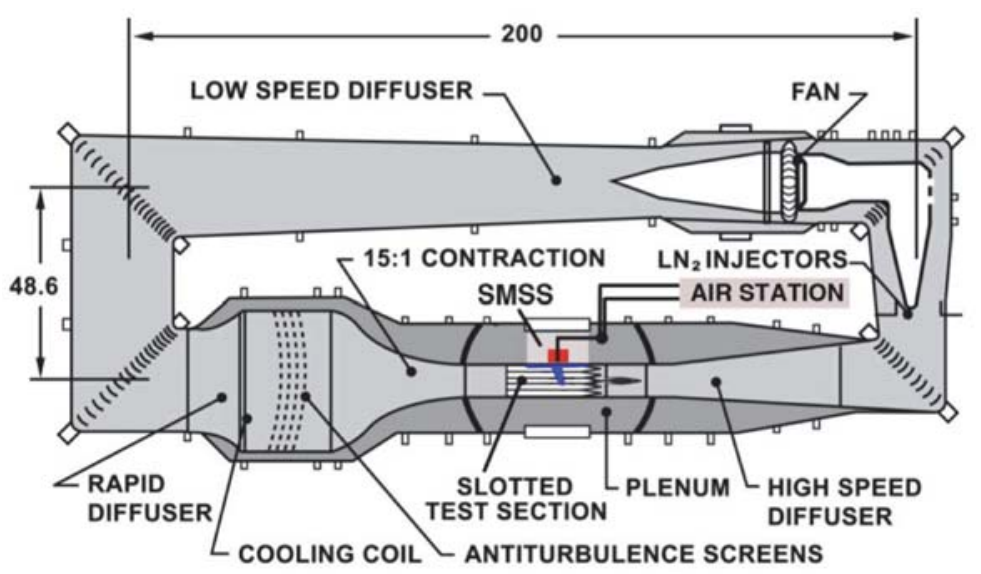

Figure 4. Sketch of the NTF highlighting the location of the SMSS

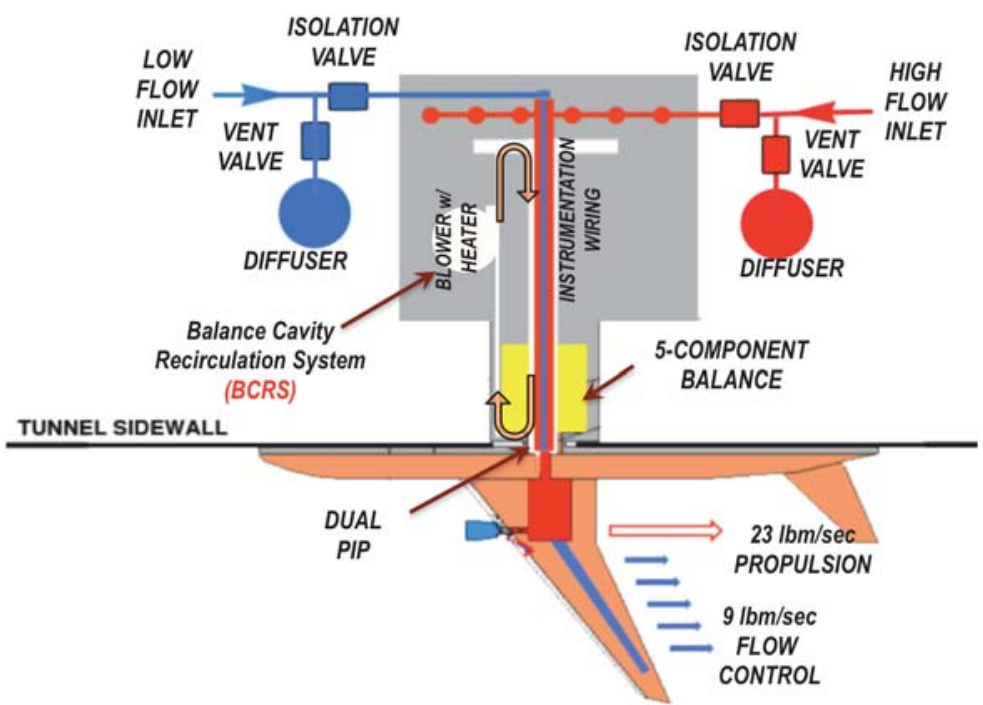

Figure 5. NTF Side Mounted Support System 
between two flow paths. The dual flow system consists of two independent supply lines that are tied to the Sidewall Mounted Support System (SMSS). The FAST-MAC model utilized only the high flow leg of this system as shown in the schematic in Fig. 6. This leg is equipped with coarse and fine control valves that can provide flow rates up to $23 \mathrm{lbm} / \mathrm{sec}$. The system has a multiple critical venturi (MCV) system located outside the tunnel plenum to capture the total weight flow. The total temperature of the model air stream can be set from $20^{\circ} \mathrm{F}$ to $120^{\circ} \mathrm{F}$ by using a steam heating system. The low temperature settings are dependent on Joule Thompson effects and thermal conduction associated with the piping located in the low temperature environment of the wind tunnel plenum.

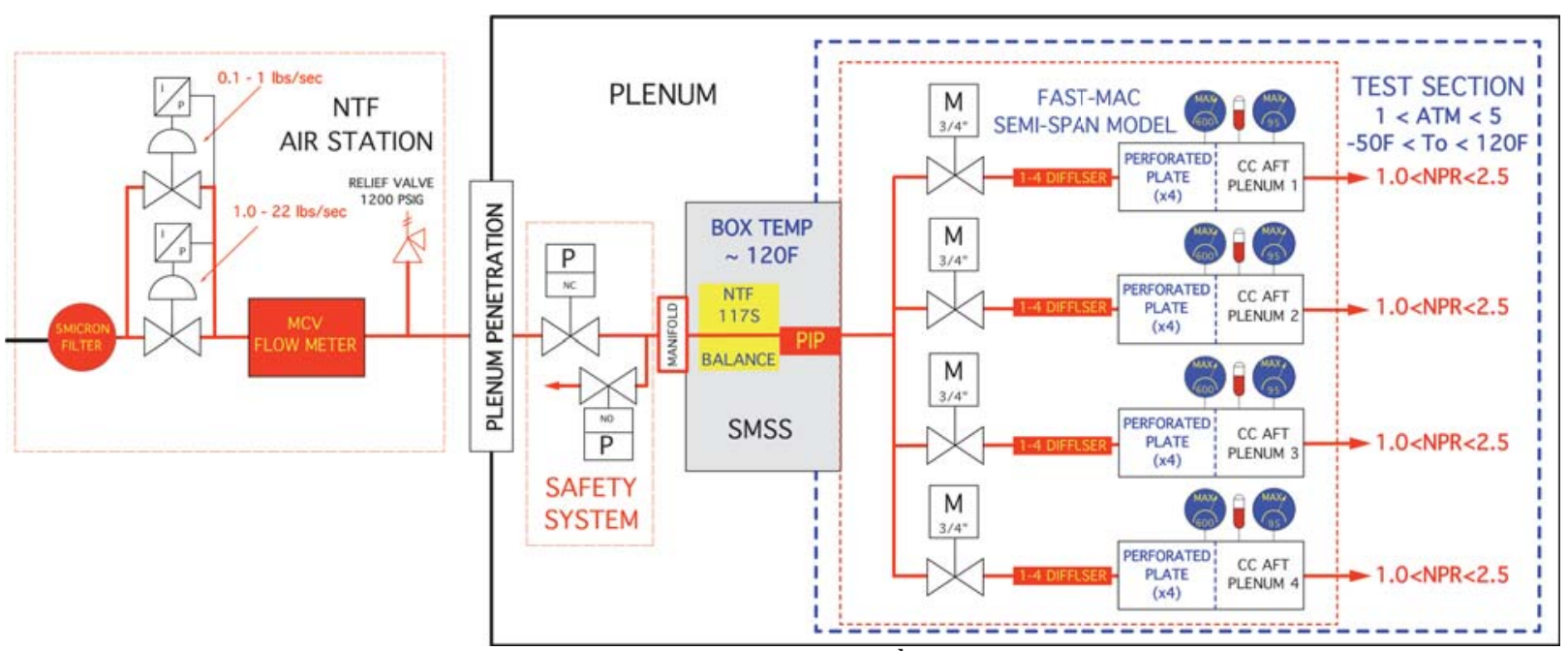

Figure 6. Schematic of the FAST-MAC air delivery system $\left(2^{\text {nd }}\right.$ flow path not shown $)$

The high-pressure air station incorporates a model protection safety system shown in Fig. 5 that limits the maximum pressure delivered to the model. The maximum pressure limit can be adjusted independently for both legs from 300 psi to 1200 psi. For the FAST-MAC model a 600 psi limit was established to protect the model in the unlikely event that the model flow path should experience a blockage. If the set pressure matches or exceeds the limit, then the supply line into the SMSS would be isolated and vented in less than 0.5 seconds.

Utilizing a semi-span capability typically increases the model size relative to a conventional sting mounted full span model. This increased model size enables higher chord Reynolds numbers and allows for higher model fidelity, as well as increased internal volume for housing the flow control mechanisms and instrumentation.

The high pressure air enters the SMSS via two independent manifolds that are connected to a rotary union before passing through the center of the balance. The co-flowing concentric air lines transition across the balance via a high-flow and low-flow bellows. Each of these bellows are designed to minimize the balance tares and momentum transfer caused by the high pressure air crossing the metric/non-metric boundary in the air delivery system.

The SMSS also provides a heated enclosure that maintains a stable temperature for the balance and the pitch mechanisms. The 5-component balance is mounted inside the SMSS as shown in Fig. 7. The balance characteristics are highlighted in Table 1.

\begin{tabular}{|c|c|}
\hline \multicolumn{1}{|c|}{ Component } & NTF 117S \\
\hline Normal Force Ibs (N) & $12,000(53,379)$ \\
\hline Axial Force lbs (N) & $1,800(8,007)$ \\
\hline Pitching Moment Ibs-in (N-m) & $90,000(10,169)$ \\
\hline Rolling Moment Ibs-in (N-m) & $669,000(7,558)$ \\
\hline Yawing Moment Ibs-in (N-m) & $100,350(11,338)$ \\
\hline
\end{tabular}

Table 1 NTF SMSS Balance Loads

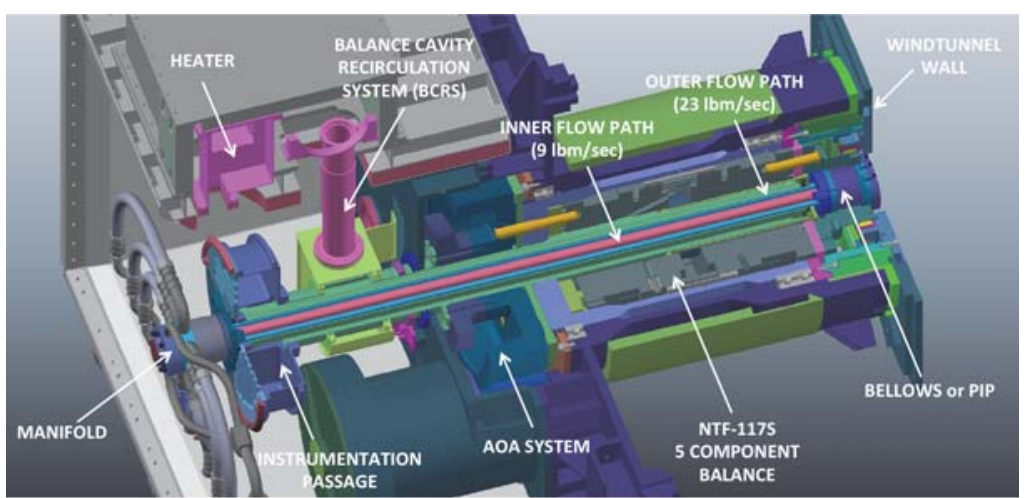

Figure 7. Cutaway sketch of the NTF SMSS highlighting the balance and co-annular flow path. 
The entire SMSS/balance/air system was calibrated to determine the pressurization and temperature effects of the two different balance/pressure interfaces. The first FAST-MAC entry utilized a convoluted bellows and the second entry utilized a Pressure Interface Piece (PIP) that is based on a schedule 40 pipe. These pressure tares are subtracted from the balance data to obtain pure aerodynamic loads ${ }^{1415}$.

\section{MODEL - Fundamental Aerodynamic Subsonic Transonic Modular Active Control Model (FAST-MAC)}

The FAST-MAC model shown in Fig. 8 is based on a supercritical wing that was designed to become a NTF standard for evaluating performance characteristics of integrated active flow control and propulsion systems. The modular design and construction of the FASTMAC model provides a capability of changing the leading edge, trailing edge, upper skin geometry (with or without engine simulators), and active or passive flow control technology. The outer mold line (OML) of the model was optimized for a cruise Mach number of 0.85 and a lift coefficient of 0.50 , at a Reynolds number based on mean aerodynamic chord of $30 \times 10^{6}$. The design utilized an unstructured Navier-Stokes flow solver USM3D ${ }^{16}$ in conjunction with the $\mathrm{CDISC}^{17}$ design code. The CDISC design method is highly efficient because the geometry changes are introduced in a manner that allows both the geometry and the simulated aerodynamic analysis to converge in unison. The flow was assumed to be fully turbulent, and a wall-function version of the SpalartAllmaras turbulence model was employed. A tangential blowing slot was added at the $85 \%$ chord location on the upper surface, and was directed over a $15 \%$ chord simple hinged flap for both the cruise and high-lift modes.

Fig. 9 shows the planform and cross-section view of the FAST-MAC semi-span model geometry and highlights the OML of the cruise configuration. The wing has an aspect ratio of 5.0, taper ratio of 0.40 , a leading edge sweep of $30^{\circ}$, and no dihedral. The wing also has a twist of $5^{\circ}$ washout that varies linearly from root to tip. Even though the wing has a moderate aspect ratio, the wing design represents the state-of-theart in transonic super-critical wing design. The chord length at the side of the fuselage is 25.0 inches, resulting in a mean aerodynamic chord of 19.4 inches. The generic fuselage is comprised of circular cross sections with a maximum width of 4.0 inches. The wing is mounted in the midfuselage position to simplify the routing of the high-pressure air supply lines. For wind tunnel testing, the model will be offset from the tunnel sidewall using a 2.0-inch non-metric standoff ${ }^{18}$, which has a profile shape identical to that of the fuselage centerline.

\section{Flap Design}

The design of the flap used in the high lift mode of operation focuses on the jet exit region $\left(r_{1}\right)$ and the transition to the OML of the cruise configuration shown in Fig. 10. The design philosophy used for the FAST-MAC model is based on a dual radius concept ${ }^{1920}$ incorporating guidelines established for circulation control airfoils having single radius Coanda surfaces with blunt trailing edges ${ }^{21,22}$. One of the key design criteria for super-circulation applications specifies an effective range of slot height to Coanda radius values from $0.01<\mathrm{h} / \mathrm{r}_{1}<0.08$. A second key design criterion specifies a range of values for the ratio of the Coanda radius to chord of $0.02<\mathrm{r} / \mathrm{c}<0.06$. While the large Coanda surfaces generate more lift than conventional high lift systems, they have significant drag in the cruise mode of operation. A compromise

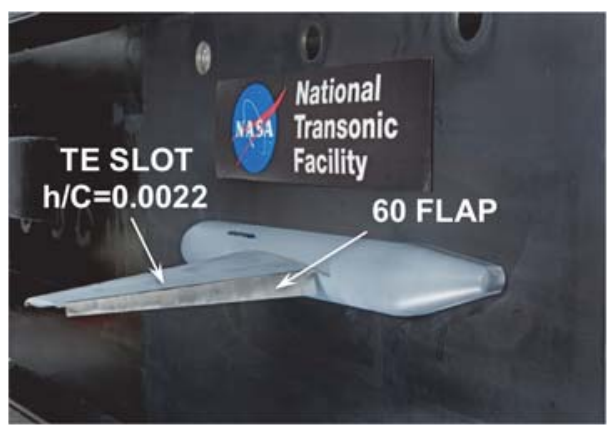

Figure 8. FAST-MAC model mounted in the NTF test section.

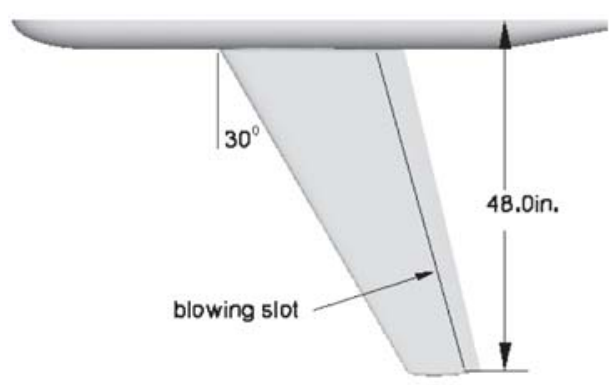

a) Planform view

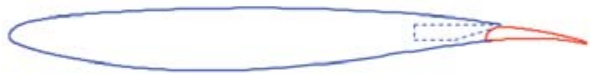

b) Super-critical cross-section view

Figure 9. NTF FAST-MAC model geometry for cruise configuration.

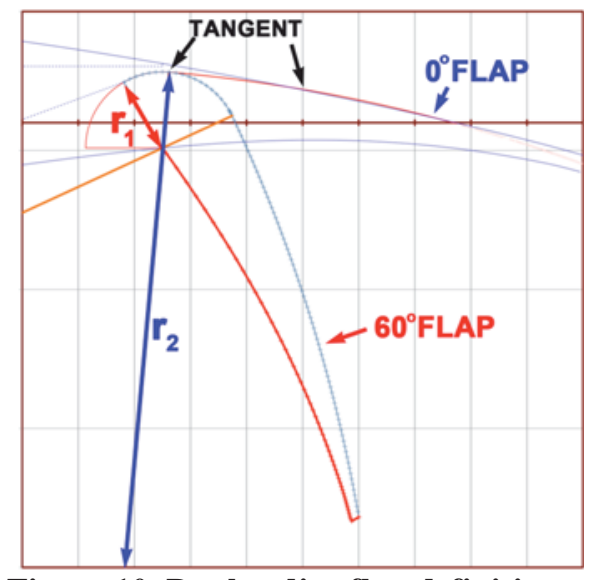

Figure 10. Dual radius flap definitions. 
between high lift and cruise configurations is a dual radius concept that focuses on efficient thrust recovery.

A conservative dual radius design would incorporate the guidelines described for the flapless configuration, however, the three-dimensional geometric constraints of the FAST-MAC configuration resulted in a more aggressive design approach. The FAST-MAC dual radius flap concept turns the high momentum the flow over a circular radius $\left(\mathrm{r}_{1}\right)$ then takes advantage of a larger turning radius $\left(\mathrm{r}_{2}\right)$, defined by the cruise geometry. The larger second radius $\left(\mathrm{r}_{2}\right)$, keeps the flow attached along the flap as the high momentum energy is reduced. The ability to keep the flow over the top of the flap from separating is typically related to the height and momentum of the jet and the turning radius of the flap.

One of the critical constraints in the FAST-MAC flap design was to have the circular arc become tangent with the upper surface mold-line of the wing so that the jet would be tangent to the local external flow. This tangent point occurs vertically from the center of rotation of the circular arc. A second critical constraint was to match the slopes at the junction of the circular arc $r_{1}$ and the cruise flap radius $r_{2}$. Even though the slopes were matched, the large difference between $r_{1}$ and $r_{2}$ (i.e. $r_{2} / r_{1}=44.7$ ) creates a discontinuity in the second derivative at the junction of the two sections. This discontinuity in the second derivative can be a source of jet separation and will be discuss later.

The maximum first radius is defined by the thickness of the wing at the flap hinge line at the $85 \%$ chord location minus the slot height. For the FAST-MAC geometry, this corresponds to an inboard to outboard spanwise variation of $0.015<\mathrm{r}_{1} / \mathrm{c}<0.018$. While the slot height was adjusted to be a constant relative to the wing chord $(\mathrm{h} / \mathrm{c}=0.0022)$, the value of $\mathrm{h} / \mathrm{r}_{1}$ varies from 0.15 inboard to 0.12 outboard.

2. Wind tunnel operations at high Reynolds number

The model design criteria were to operate at the maximum pressure limits of the facility and a temperature range of $-50^{\circ} \mathrm{F}$ to $120^{\circ} \mathrm{F}$. While a typical NTF wind tunnel model such as the FAST-MAC accurately characterizes outer mold lines (OML) of an advanced high Reynolds number wing model, the internal flow paths are only representative at the jet exit. As shown in Fig. 11, high dynamic pressures are generally required to achieve high Reynolds number conditions for a typical semi-span NTF model. As such, the high model loading and resulting high model stresses limited accurate internal flow path geometries due to strength of materials and limited volume.

\section{Flow Path Design}

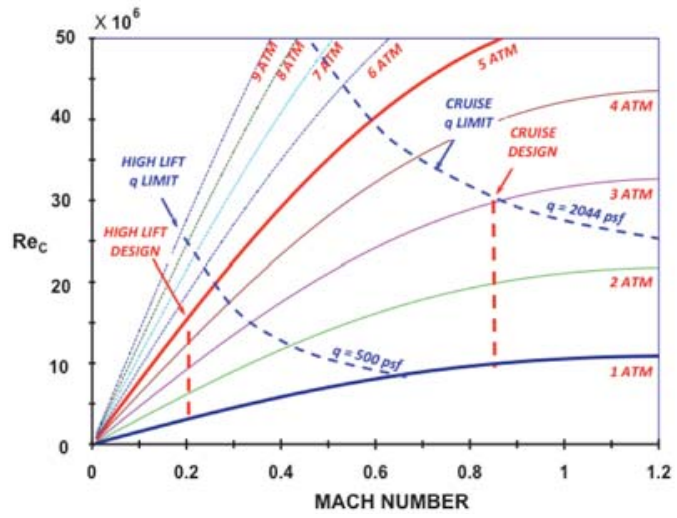

Figure 11. NTF operating envelope for FAST-MAC, $\mathrm{To}=-50^{\circ} \mathrm{F}, \mathrm{MAC}=19.4$ inches.

Two examples of the correlation of weight flow and NPR are shown in Fig. 12 for a free stream Mach number of 0.2 at 5 atmospheres. The two average slot heights shown correspond to $\mathrm{h} / \mathrm{c}=0.0032$ and $\mathrm{h} / \mathrm{c}=0.0022$. These examples represent the weight flow requirements for the FAST-MAC model and the NTF air delivery system.

The FAST-MAC model utilized multiple flow paths shown in Fig. 13, to achieve tailored lift and thrust performance along the span of the CC flap. The flow path for the FAST-MAC model was divided into four sections along the span of the model. Each section had its own flow control valve located in the fuselage that fed a rapid diffuser located in the wing box shown in Fig. 14. The splitter/diffuser expanded and subdivided the flow into four individual flow paths that turned the flow into one of the four aft plenums distributed

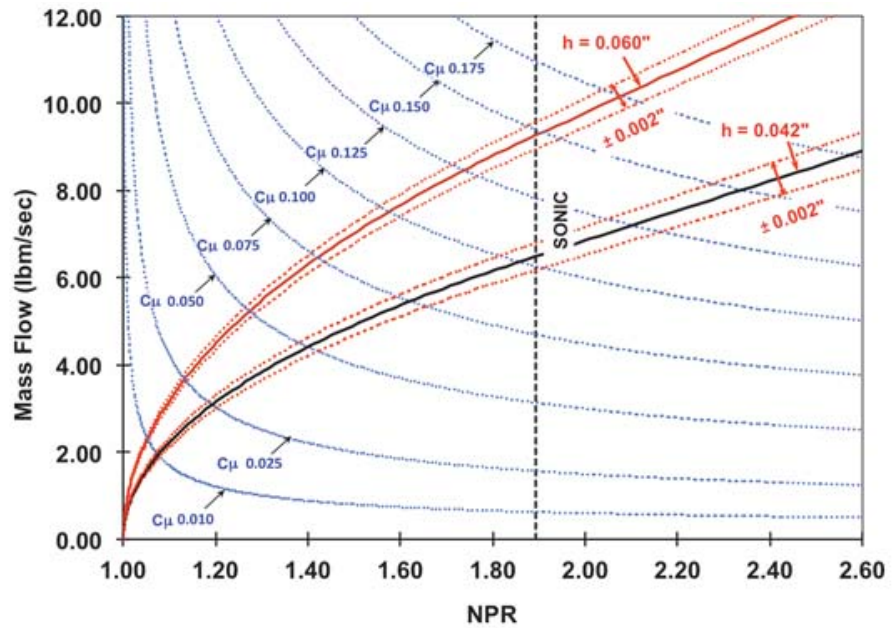

Figure 12. Circulation control jet parameters, $P_{T}=5$ Atm, Mach $=0.2, \mathrm{To}_{\mathrm{JET}}=30^{\circ} \mathrm{F}$. along the span of the wing. 
Each plenum had four perforated plates designed to maintain flow uniformity into the aft plenum settling chamber. The aft section of the plenum had a 6 to 1 contraction ratio to the jet exit for the $\mathrm{h} / \mathrm{c}=0.0032$ configuration and a contraction ratio of 12 to 1 for the $\mathrm{h} / \mathrm{c}=0.0022$ configuration. This was based on an averaged slot height of 0.060 inch for the $\mathrm{h} / \mathrm{c}=0.0032$ configuration and a 0.042 inch slot height for the $\mathrm{h} / \mathrm{c}=0.0022$ configuration. Once the flow passes through the jet exit it then proceeds onto a dual radius flap ${ }^{23}$ as shown in Fig. 15. The skin that forms the upper wall of the plenum is 0.010 inches thick at the trailing edge located at the jet exit. Without any internal support, the skin will move allowing the slot height to increase. To prevent this, stationary aerodynamic standoffs were designed into the aft plenum along the span to maintain a known slot height as shown in Fig. 16. The slot height varies along the tapered chord to form a constant $\mathrm{h} / \mathrm{c}=0.0033$ (or $\mathrm{h} / \mathrm{c}=0.0022$ ) for the high lift configuration and constant $\mathrm{h} / \mathrm{c}=0.0022$ for the cruise configuration. The slot heights were adjusted with 0.0002 inch shims to maintain an accuracy of \pm 0.001 inch along the span. During the first entry the slot height was measured real time with capacitance type gages at four spanwise locations to capture slot height changes due to internal pressure or temperature variations. The slot height measured at the four spanwise locations varied less than $0.25 \%$ from their initial height when pressurized to the maximum plenum pressure. No influence of temperature on slot height movement was detected.

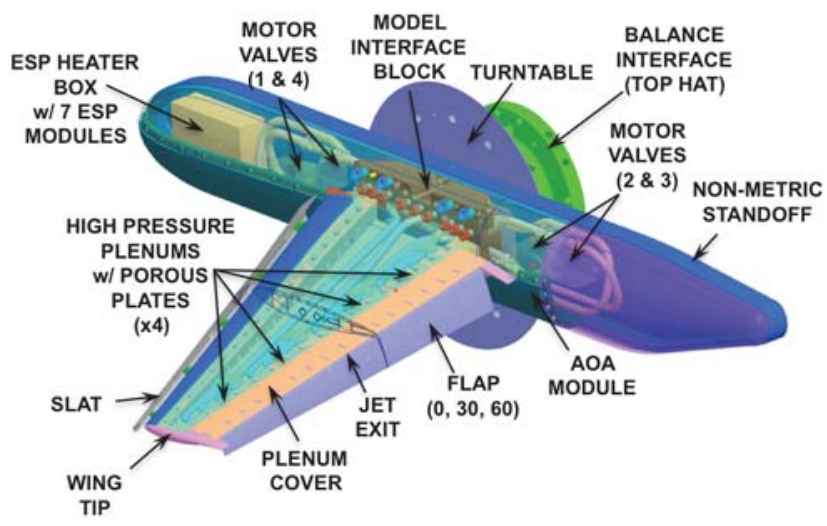

Figure 13. Cutaway view of the FAST-MAC model, in high-lift mode highlighting multiple internal flow paths.

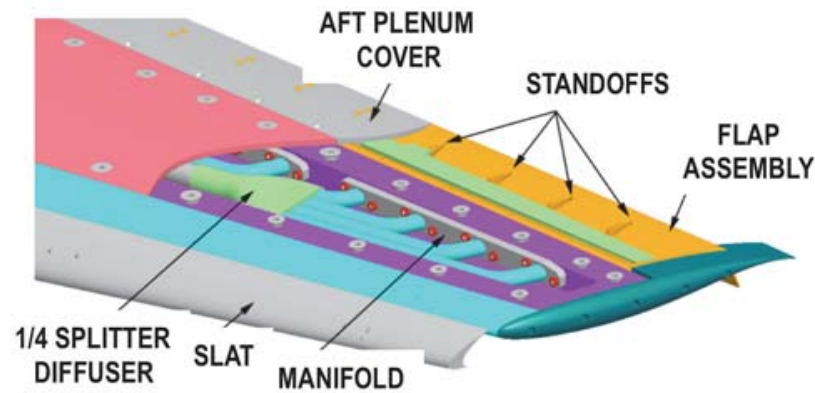

Figure 14. Cutaway sketch of the FAST-MAC model highlighting the wing tip flow path.
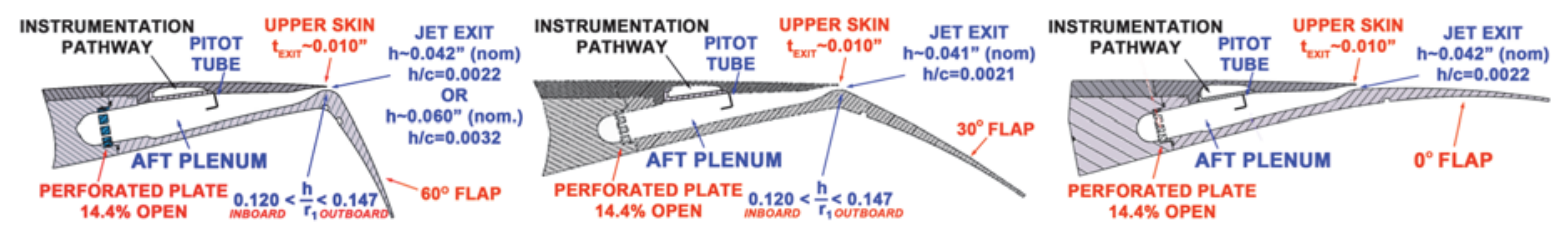

Figure 15. FAST-MAC aft plenum and flap configurations.

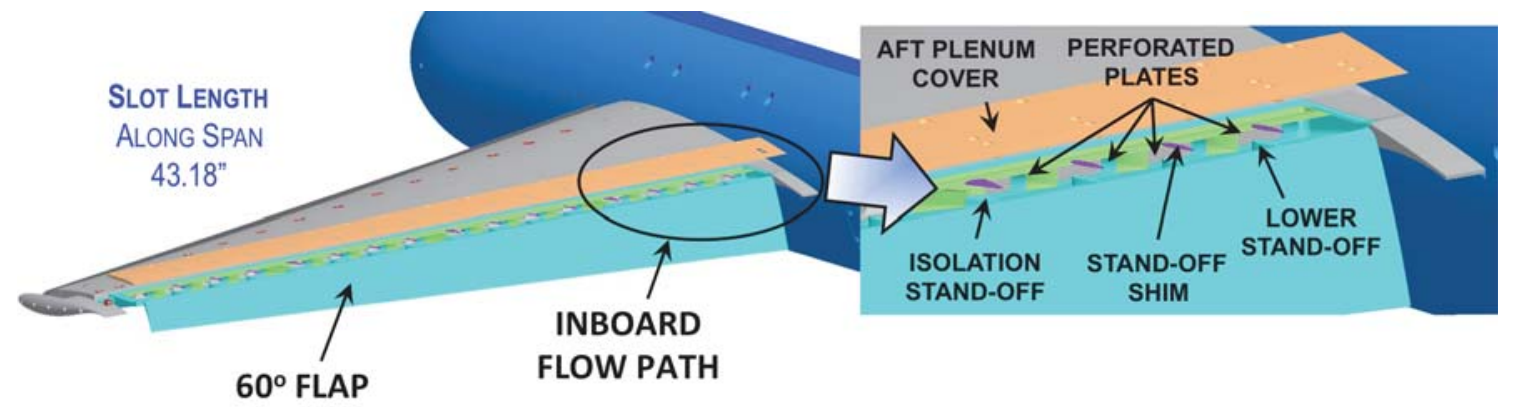

Figure 16. FAST-MAC aft-plenum configuration. 


\section{E. Perforated Plate Design}

Since the flow is divided into four internal flow paths it was necessary to place weight flow measurement devices into each flow path of the model. A perforated plate design that spanned each flow path was projected to remain choked so that the independent weight flow of each path could be determined. The design of the perforated plate became the critical step of the FAST-MAC internal flow path design because it established the maximum internal pressure, the maximum flow rate, and the flow distribution along the span of the model. The resistance coefficient $\zeta$ is shown in Eqn. 4 as a function of the pressure drop across the perforated plate and the dynamic pressure upstream of the plate. The resistance coefficient, $\zeta$ can also be written in terms of the perforated plate open area ratio, $\bar{f}$, as shown in Eqn. $5^{24}$, where $\tau$ is hole boundary layer growth factor, and $\ell$ is related to the internal tube roughness coefficient (typical $\ell=0.02$ for drilled holes). Eqn. 6 defines the open area ratio, where $\mathrm{A}_{o}$ is the area of a single orifice and $\mathrm{A}_{\text {PLATE }}$ is the area of the pressurized plate without holes. Rearranging Eqn. 4 and adding an inlet compressibility factor $k_{m}{ }^{25}$, the $\Delta \mathrm{p}$ across the perforated plate becomes Eqn. 7, where $k_{m}$ is a function of openness, $\bar{f}$ and inlet perforated plate Mach number as shown in Fig. 17. It is assumed that the inlet and exit flow collapses to uniform velocity distribution approximately 10 orifice diameters upstream and downstream of the perforated plate as depicted in Fig. 18. It is also assumed that the upstream velocity is equal to the downstream velocity.

$$
\begin{aligned}
& \zeta=\frac{\Delta p}{0.5 \rho_{u} U_{u}^{2}} \\
& \zeta=\frac{\Delta p}{0.5 \rho_{u} U_{u}^{2}}=\frac{\left[0.5(1-\bar{f})^{0.75}+\tau(1-\bar{f})^{1.375}+(1-\bar{f})^{2}+\lambda\left(\frac{\ell}{d_{h}}\right)\right]}{\overline{f^{2}}}
\end{aligned}
$$

where $\tau=(2.4-\bar{\ell})^{\varphi(\bar{\ell})}$ and $\varphi(\bar{\ell})=0.25+\frac{0.535 \bar{\ell}^{\overline{8}}}{0.05+\overline{\ell^{7}}}$ and $\bar{\ell}=\frac{\ell}{d_{h}}$

$$
\bar{f}=\frac{\sum A_{O}}{A_{P L A T E}}(6) \quad \Delta p=k_{m} \xi\left(0.5 \rho_{u} U_{u}^{2}\right)
$$

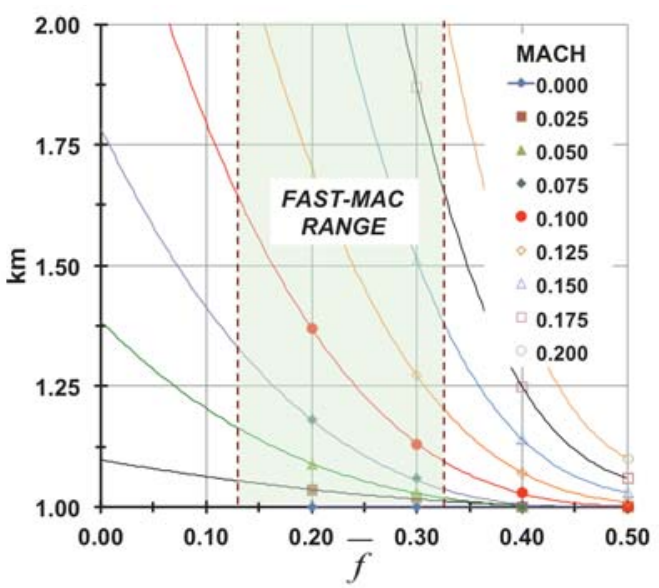

Figure 17. Perforated plate compressibility factor for upstream Mach number and openness ratio

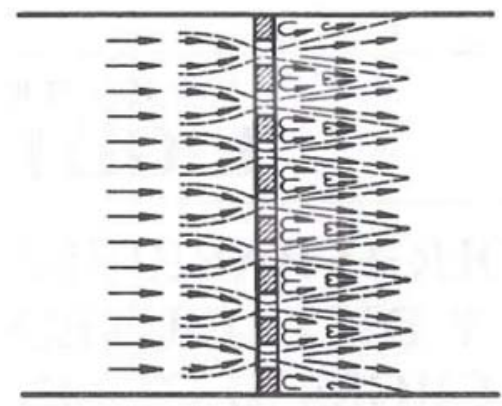

Figure 18. Flow characteristics through a perforated plate. 
A staggered orifice configuration was designed for the FAST-MAC perforated plates. The following relationships were used to determine the number of orifices, the transverse spacing, S1, longitudinal spacing, S2, and pitch angle for the perforated plate shown in Fig. 19.

$$
n_{\text {or }}=\frac{1.27 A_{P L A T E} \bar{f}}{d_{o r}^{2}}
$$

For a pitch angle $(\theta)$ of 60 degrees

$$
\begin{aligned}
& S_{1}=\frac{0.82 d_{o r}}{\sqrt{\bar{f}}} \\
& S_{2}=\frac{0.95 d_{o r}}{\sqrt{f}}
\end{aligned}
$$

The perforated plate design process was an iterative method that focused on model safety, weight flow limits, and measurement requirements. The maximum openness ratio was limited to orifice areas that were open enough to pass the required flow rate. The minimum openness ratio was also limited to orifice areas that would not exceed the maximum model pressures. These pressures are a function of the backpressure and perforated plate pressure drop at maximum flow conditions. Since the perforated plate is exposed to the stagnation temperatures of the facility (e.g. $\left.-50^{\circ} \mathrm{F}\right)$ there was a concern that a blockage could occur if ice formed in the orifices due to any moisture in the system. This would result in closing the open area and increasing the upstream pressure beyond the model limits. To minimize the potential icing conditions the open area was optimized for the largest open area while meeting the conditions described above.

To determine the weight flow of each flow path, it was initially assumed that the flow would choke at the perforated plate. The perforated plate openness ratio of 0.332 used for the first iteration of the FAST-MAC model failed to choke and had undulating flow non-uniformity along the span for the targeted NPRs that ranged from 1.2 to 2.2. A post-test benchtop simulator of a single flow path was used to evaluate different openness ratios and hole distributions prior to the second wind tunnel test of the FAST-MAC. Three different perforated plate designs shown in Fig. 19 were evaluated. Since the FAST-MAC perforated plate was mechanically difficult to change it was determined that a single perforated plate would be required to support two different $\mathrm{h} / \mathrm{c}$ configurations. The maximum flow conditions are shown in Figs. 20 and 21. The two smallest openness ratios used for the $\mathrm{h} / \mathrm{c}=0.0033$ did not exceed the $600 \mathrm{psig}$ pressure drop limit and was choked for the highest tunnel pressure of 5 atmospheres. However none of the perforated plates were choked for the $h / c=0.0022$ configuration. This was also the true for conditions at lower weight flows associated with lower tunnel pressures needed for lower Reynolds number testing. Therefore the choked condition requirement for the perforated plate was dropped and flow uniformity was emphasized.

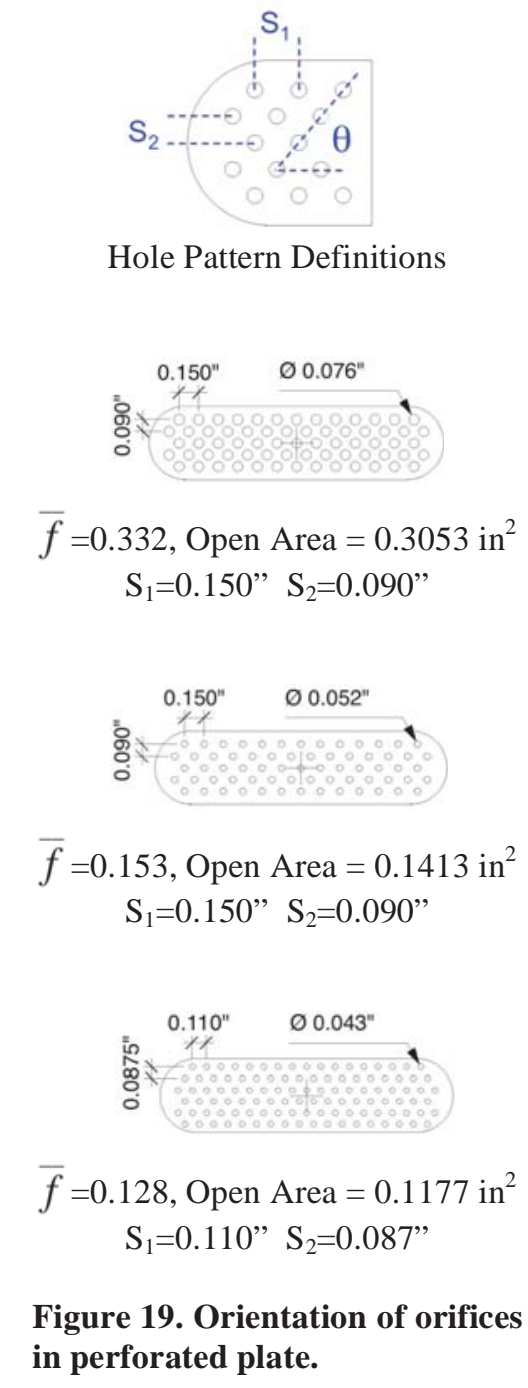




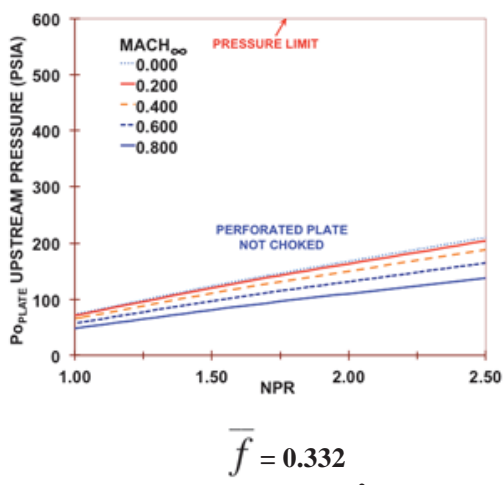

$A_{0}=4.8852$ in $^{2}$

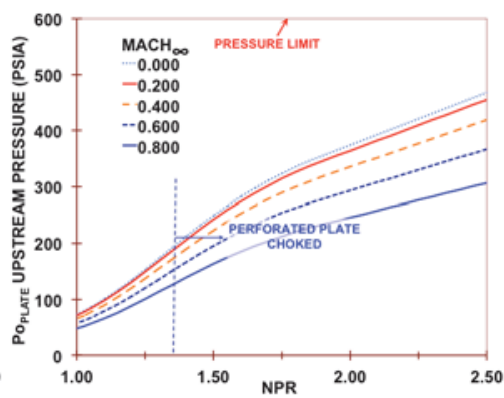

$\bar{f}=\mathbf{0 . 1 5 2}$

$A_{0}=2.2513$ in $^{2}$

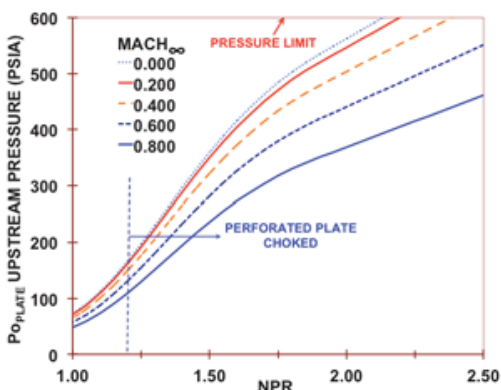

$\bar{f}=\mathbf{0 . 1 2 8}$

$\mathrm{A}_{0}=1.8835 \mathrm{in}^{2}$

Figure 20. Predicted perforated plate performances. Mach $=0.2, P 0=5 \mathrm{ATM}, \mathrm{To}=-50^{\circ} \mathrm{F}, \mathrm{To}_{\mathrm{JET}}=30^{\circ} \mathrm{F}$,

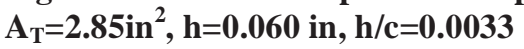

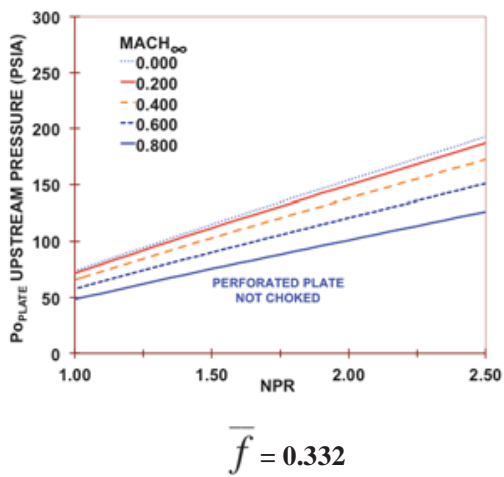

$A_{0}=4.8852$ in $^{2}$

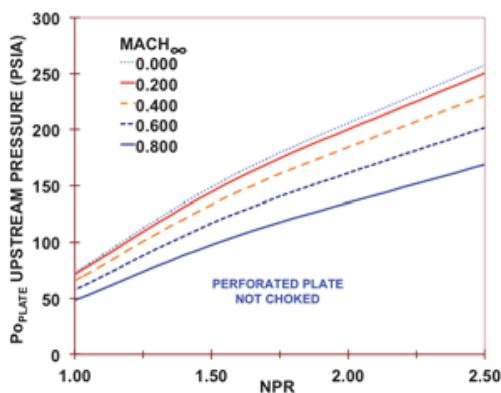

$\bar{f}=\mathbf{0 . 1 5 2}$

$A_{0}=2.1513$ in $^{2}$

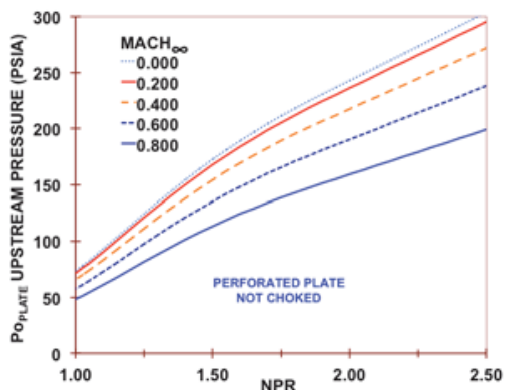

$\bar{f}=\mathbf{0 . 1 2 8}$

$\mathrm{A}_{0}=1.8835 \mathrm{in}^{2}$

Figure 21. Predicted perforated plate performances. Mach $=0.2, P o=5 \mathrm{ATM}, \mathrm{To}=-50^{\circ} \mathrm{F}, \mathrm{To}_{\mathrm{JET}}=30^{\circ} \mathrm{F}$, $A_{T}=1.995 i^{2}, h=0.042$ in, $h / c=0.0021$.

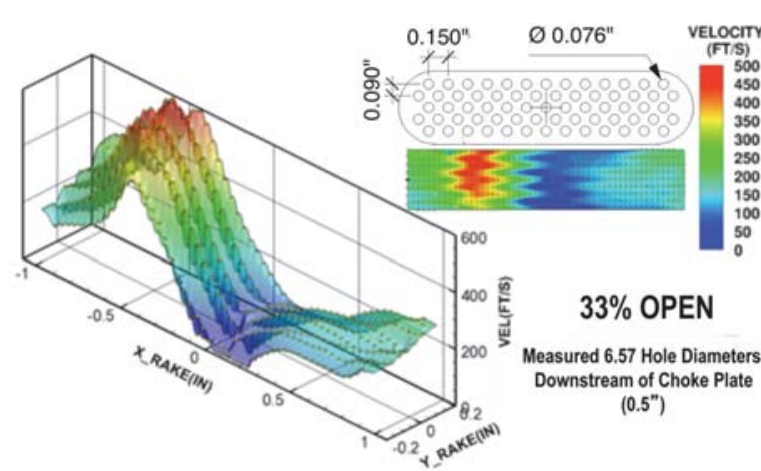

Figure 22. Velocity distribution downstream of the initial FAST-MAC perforated plate having a 0.332 openness ratio

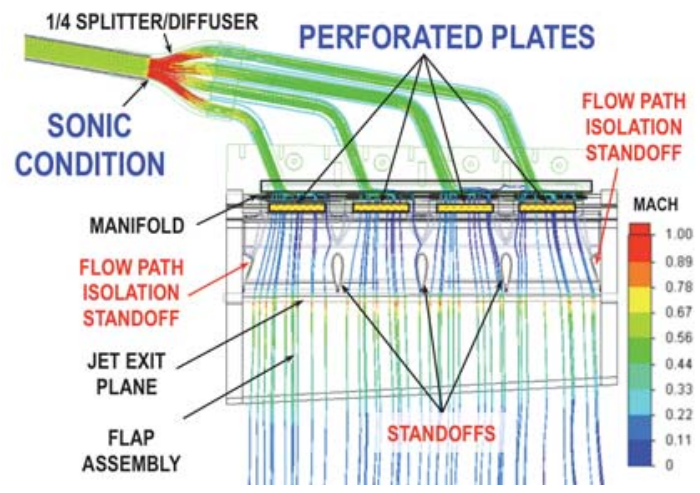

Figure 23. CFD simulation of the single flow path for the FAST-MAC bench top configuration

The basis for the perforated plate design assumes a uniform inlet flow. The bench-top simulator evaluation revealed that the inlet conditions were non-uniform as shown in the measured exit velocities just downstream of the 0.332 perforated plate, shown in Fig. 22. A CFD simulation ${ }^{26}$ of a single flow path showed that the inlet flow is not normal to the perforated plate and that the small plenum associated with the inlet manifold does not diffuse the flow uniformly onto the perforated plate as shown in Fig. 23. The non-uniform flow impingement onto the perforated plate resulted in large spanwise variations that included separated flow in the aft plenum that was propagated to the jet exit. In an attempt to resolve this issue, each of the four perforated plates was customized for flow uniformity by plugging individual orifices. The initial focus was to develop the 0.128 perforated plate, however plugging the plate 
to achieve flow uniformity resulted in pressure differentials that exceeded the $600 \mathrm{psia}$ safety limit for the $\mathrm{h} / \mathrm{c}=0.332$ configuration of the model. Developing the 0.152 perforated plate resulted in a unique orifice distribution for each plate due to slight differences in the inlet flow into the manifold. The orifice and flow distributions for each plate are shown in Fig. 24. The flow uniformity continued to improve through the aft plenum and contraction resulting in a uniform flow at the jet exit.
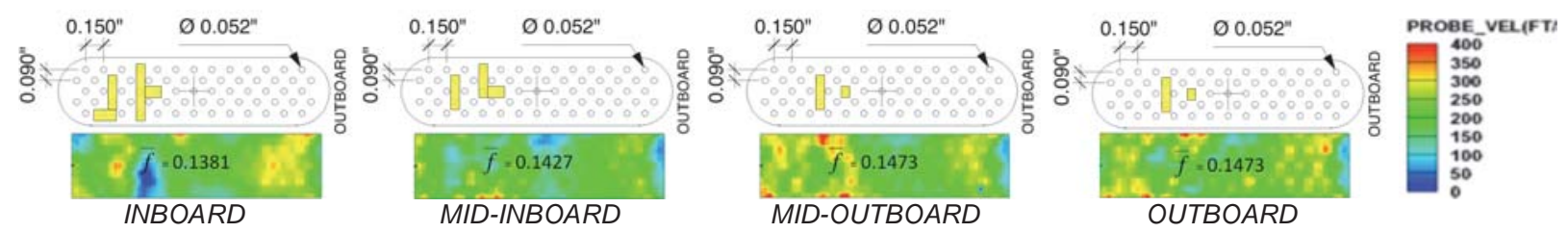

Figure 24. Customized FAST-MAC perforated plate orifice distribution and flow pattern measured 9.6

hole diameters downstream of plate. Average flow path openness ratio, $\bar{f}=\mathbf{0 . 1 4 3 8}$.

\section{Model Flow Characteristics}

The FAST-MAC model was designed to enable the flow to be tailored along the span by independently controlling the flow through any combination of the four flow paths distributed along the span of the wing. It is generally accepted that the loading on the model is best described by the momentum coefficient as illustrated in Fig. 3. However, setting a specific $\mathrm{C} \mu$ proved to be time consuming and often difficult to repeat, so NPR was used to manage the blowing with few exceptions throughout the test. The typical NPR settings of each flow path were matched for the majority of the testing, however a limited number of runs focused on tailored blowing that consisted of only one or two flow paths being active.

The correlation of the performance that is measured by the balance is based on the averaged $\mathrm{C} \mu$. The jet exit total pressure parameters used in the calculation of velocity and $\mathrm{C} \mu$ have measurement uncertainties that are less than $\pm 0.1 \%$ of reading for the range of flow conditions tested. The weight flow calibration of each FAST-MAC flow path was determined using the NTF air station's MCV system ${ }^{27}$ identified in Fig. 6. This flow standard has an uncertainty of $\pm 0.35 \%$ of reading ${ }^{28}$ for the weight flows of interest.

The variation of $\mathrm{C} \mu$ along the span is a function of slot geometry and weight flow. Therefore, even for a fixed jet exit Mach number, the weight flow varies with changing slot area. For the $60^{\circ}$ flap configuration, the measured exit areas are shown in Fig. 25. These measured areas are biased at the ends by fixed model parameters that are based on the maximum slot height that would be tested, i.e. $\mathrm{h} / \mathrm{c}=0.0033$. Similar slot height distributions were measured for the $\mathrm{h} / \mathrm{c}=0.0022$ configuration on the $0^{\circ}$ flap and $30^{\circ}$ flap.

An example of the momentum coefficient variation for a fixed NPR along the span is shown in Fig. 26. The variation of $\mathrm{C} \mu$ along span is 1.6 times larger at the inboard portion of the wing compared to the outboard wing section. Ignoring any upstream non-uniform flow interactions, such as streamwise vorticies eminating from the slat, the ideal lift performance for a fixed spanwise NPR is less at

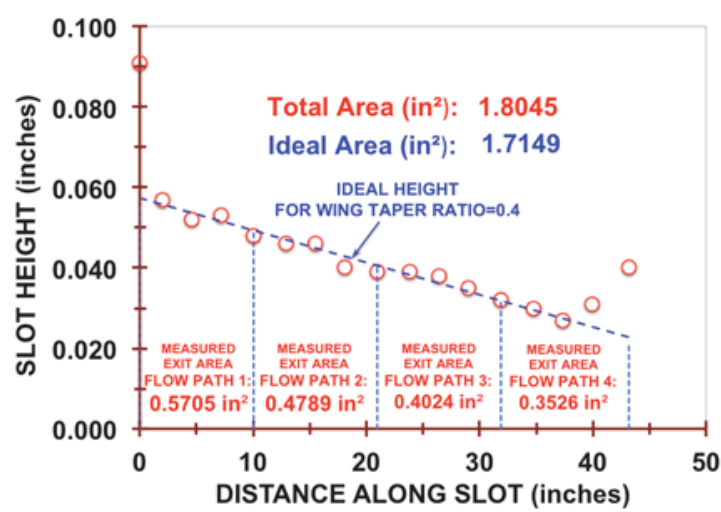

Figure 25. Slot height measurements for the $60^{\circ}$ flap, $\mathbf{h} / \mathbf{c}=\mathbf{0 . 0 0 2 2}$ configuration

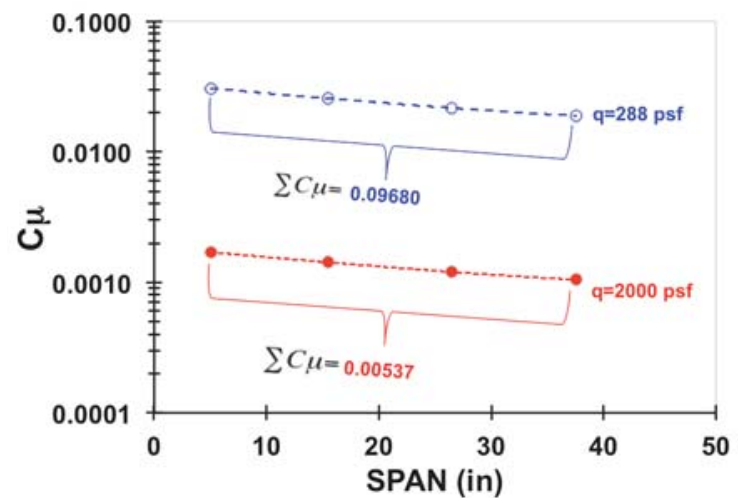

Figure 26. Spanwise momentum coefficient for high lift $(\mathbf{P o}=5 \mathrm{ATM})$ and cruise $(\mathbf{P o}=3 \mathrm{ATM})$ configurations, NPR $=1.89$, $T o=-50^{\circ} \mathrm{F}, \mathrm{T}_{\mathrm{JET}}=30^{\circ}$, $\mathbf{h} / \mathbf{c}=\mathbf{0 . 0 0 2 2}$. 
the tip than at the inboard section. This ideal performance assumes that the jet remains attached all the way to the trailing edge of the flap.

\section{A. Flow path calibration}

The correlation of the model performance that is determined from the 5-component balance can be made with the weight flow measurements obtained directly with the air stations MCV system. To augment this measurement and to characterize the spanwise momentum coefficient variations described above, or for conditions where NPR was not constant along the span it was necessary to calibrate the weight flow through each flow path independently. It is assumed that the four independent calibrations can be applied to any combination of active flow paths to achieve the total flow condition measured by the MCV. As part of the evaluation of this approach the sectional nozzle efficiency needed to be established.

The full-span blowing configuration with a constant spanwise NPR was used to establish the baseline nozzle efficiency. The nozzle efficiency is characterized by the nozzle discharge coefficient, defined as the ratio of measured weight flow to ideal weight flow, where the ideal weight flow is dependent on whether the exit condition is subsonic or supersonic as shown in Eqn. 11a and 11b. The measured weight flow calibration through each flow path is a function of exit area, backpressure, and temperature at the jet exit.

When operating with less than the full span flow paths (e.g. one, two, or three flow paths), the boundary on at least one side of the plenum is not well defined since the

If NPR < NPR $\mathrm{CRITICAL:}$

$$
W_{l}=P O_{J E T} A_{T}\left(\frac{1}{N P R}\right)^{\frac{1}{\gamma}} \sqrt{\frac{g \gamma}{R T O_{J E T}} \frac{2}{(\gamma-1)}\left[1-\frac{1}{N P R}^{\frac{(\gamma-1)}{\gamma}}\right]}
$$

If NPR > NPR

$$
W_{I}=P O_{J E T} A_{T} \sqrt{\frac{g \gamma}{R T O_{J E T}}\left[\frac{2}{(\gamma-1)}\right]^{(\gamma \gamma-1)}}
$$
average of 8.3 slot heights upstream of the jet exit for the $\mathrm{h} / \mathrm{c}=0.0022$ configuration. This enables the flow to expand into the unused flow path, thus creating an effective exit area that is larger than what is defined by the projection of the area between the trailing edges of the insolation standoffs. The effective areas of the individual flow paths are used to adjust the ideal weight flow to match the discharge coefficient of the all-blowing configuration at an NPR of 2.2. The nozzle discharge coefficients presented in Fig. 27 were determined from the ratio of the measured nozzle weight flow and the nozzle ideal weight flow that are based on effective areas of each single flow path. The reduced discharge coefficients that occur in the range of $1.5<\mathrm{NPR}<1.9$ is consistent with compressibility effects associated with a normal shock beginning to form at the jet exit. An example of the weight flow characteristics for the 1 atmosphere condition is shown in Fig. 28 . The deviation of the effective flow path areas are $6 \%, 20 \%, 25 \%$, and $14 \%$ higher than the measured areas for the inboard to the outboard flow paths.

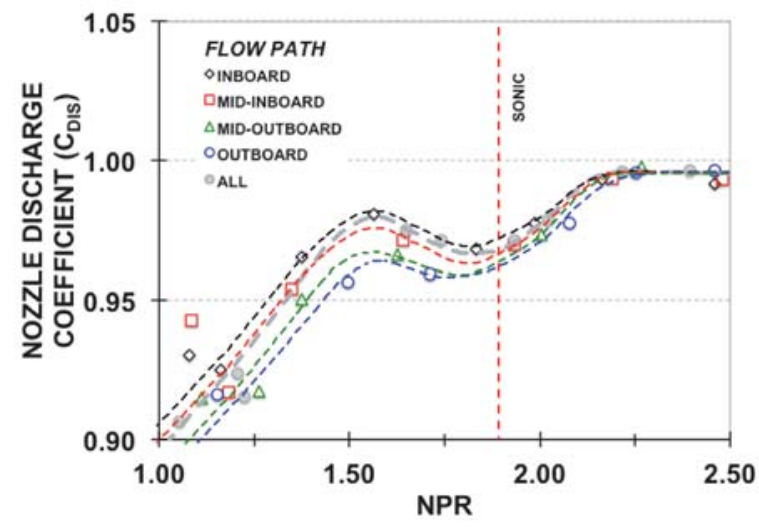

Figure 27. Nozzle discharge coefficients for the $60^{\circ}$ flap, $h / c=0.0022$ configuration, $\quad$ Po=1ATM, $\mathrm{T}_{\mathrm{JET}}=40^{\circ} \mathrm{F}$.

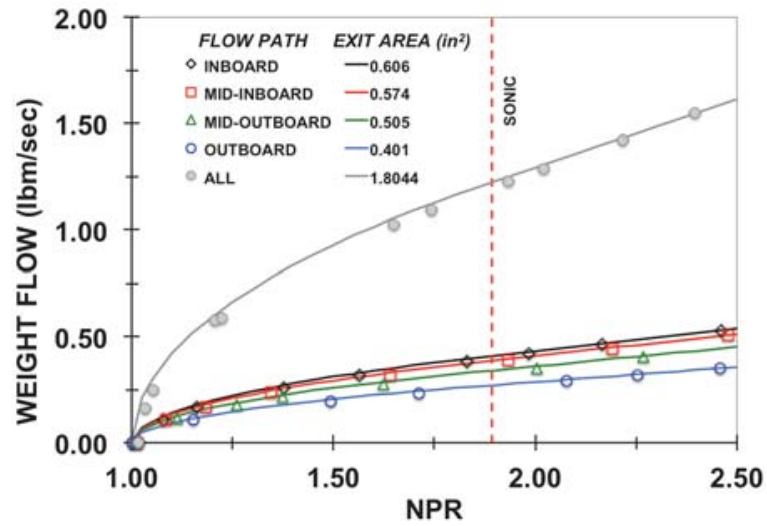

Figure 28. Weight flow calibration of the four FAST-MAC flow paths Po=1ATM, $\mathrm{T}_{\mathrm{JET}}=40^{\circ} \mathrm{F}$. Symbols represent measured weight flow, fitted line represents ideal weight flow 


\section{B. Flow path modeling}

To characterize the flow behavior for the four individual flow paths described above, an analysis of variance (ANOVA) method for estimating variance components was applied to the weight flow data. This multiple-variable mathematical model is used to estimate the weight flow imparted on the model as a function of spanwise blowing. When calibrating the flow system, a set of independent variables (NPRs and backpressures) is applied to the model resulting in the predicted variable (weight flow). The range of the calibration NPRs applied to the model during the calibration process defines the 'design space' and was limited to $1<\mathrm{NPR}<2.5$ and $1<\operatorname{Ps}<5$. Historically, the desired schedule used to calibrate a flow system (which defines the weight flow combinations and the order that they are to be performed) should have been random. However, due to cost and schedule constraints, the run schedule became a sequential process that starts from a minimum flow condition and extends to the maximum flow condition then returns to the minimum flow condition.

The multi-variable calibration model used for the flow system is based on a Taylor series, and is given by Eqn. 12 , where $\mathrm{k}$ is the number of independent variables $(\mathrm{k}=5), x_{i}$ is the $i_{t h}$ independent variable, and $\beta$ terms represent the calibration coefficients determined from a multiple linear regression procedure ${ }^{29}$. It was determined that that the

$y=\beta_{O}+\sum_{i=1}^{k} \beta_{i} x_{i}+\sum_{i=1}^{k-1} \sum_{j=i+1}^{k} \beta_{i j} x_{i} x_{j}+\sum_{i=1}^{k} \beta_{i i} x_{i}^{2}$ second order effects were insignificant resulting in a modified linear model. The calibration coefficients for this model are shown in Table 2. The resulting predicted responses are shown in Fig. 29.

\begin{tabular}{|c|c|c|c|c|c|c|c|c|c|}
\cline { 2 - 9 } & \multicolumn{4}{|c|}{ MAIN EFFECTS } & \multicolumn{3}{c|}{ INTERACTIVE EFFECTS } \\
\cline { 2 - 9 } & $P_{\infty}$ & $\begin{array}{c}\text { NPR 1 } \\
\text { OUTBOARD }\end{array}$ & $\begin{array}{c}\text { NPR 2 } \\
\text { MID- } \\
\text { OUTBOARD }\end{array}$ & $\begin{array}{c}\text { NPR 3 } \\
\text { MiD- } \\
\text { INBOARD }\end{array}$ & $\begin{array}{c}\text { NPR 4 } \\
\text { INBOARD }\end{array}$ & $P_{\infty}($ NPR1) & $P_{\infty}$ (NPR2) & $P_{\infty}($ NPR3) & $P_{\infty}$ (NPR4) \\
\hline$\beta_{0}$ & $\beta_{1}$ & $\beta_{2}$ & $\beta_{3}$ & $\beta_{4}$ & $\beta_{5}$ & $\beta_{12}$ & $\beta_{13}$ & $\beta_{14}$ & $\beta_{15}$ \\
\hline 0.34616 & -0.07487 & 0.05365 & -0.02870 & -0.14139 & -0.24225 & 0.01292 & 0.01848 & 0.02388 & 0.02739 \\
\hline
\end{tabular}

Table 2. Calibration coefficients for weight flow model (reference equation 12), $h / c=0.0022$
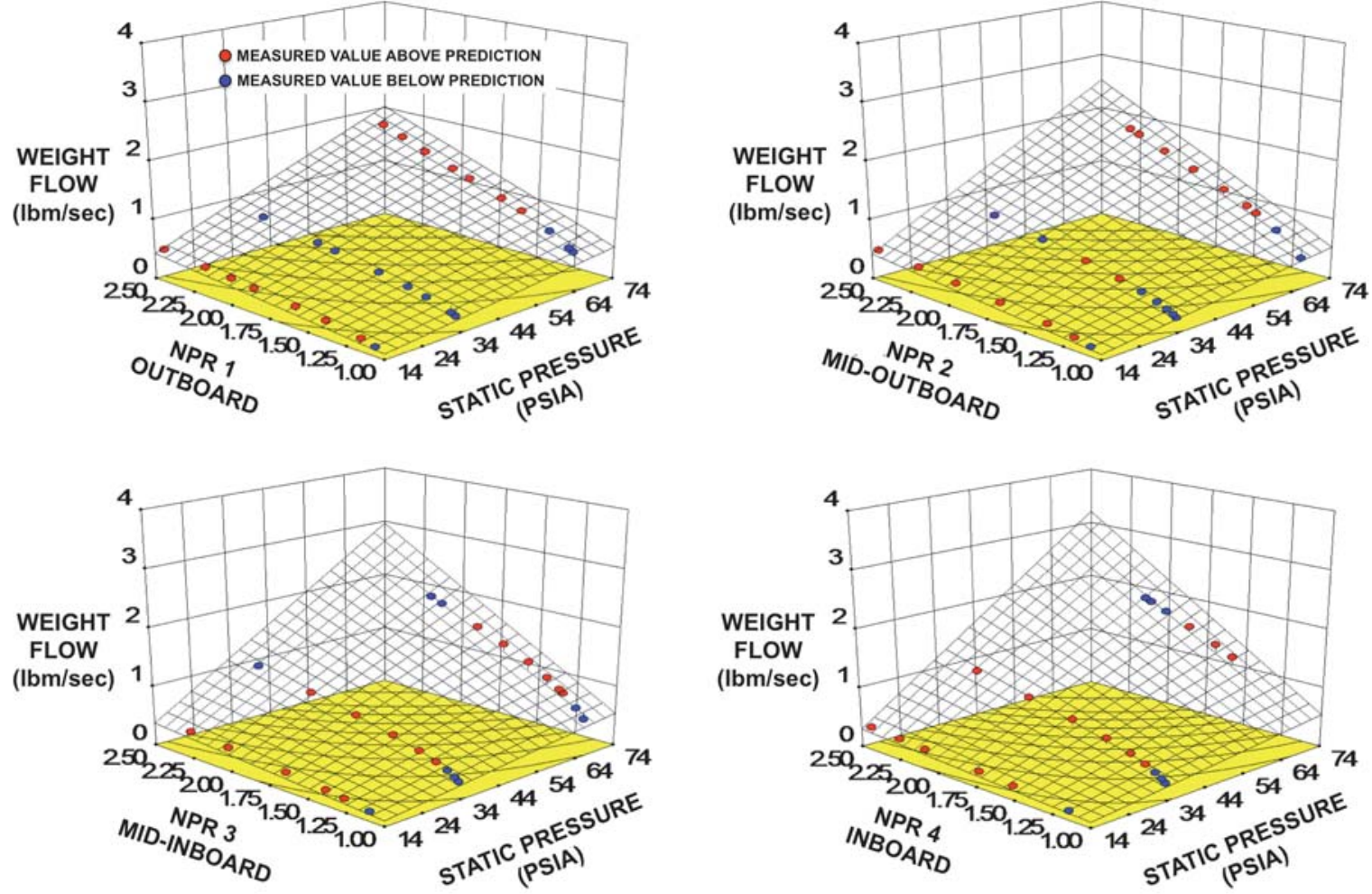

Figure 29. Predicted response for single flow paths of the $60^{\circ}$ flap, $h / c=0.0022$ configuration 
The standard error of prediction, or prediction variance, is a computed value that provides an estimate on the quality of the predicted responses and is based entirely on the experimental design. Examples of the standard error predictions for a single flow path response and for an all-blowing response are shown in Fig. 30. The remaining three single flow path responses are similar to the outboard flow path configuration resulting in a combined $\mathrm{R}^{2}$ value of 0.98 for this mathematical model.

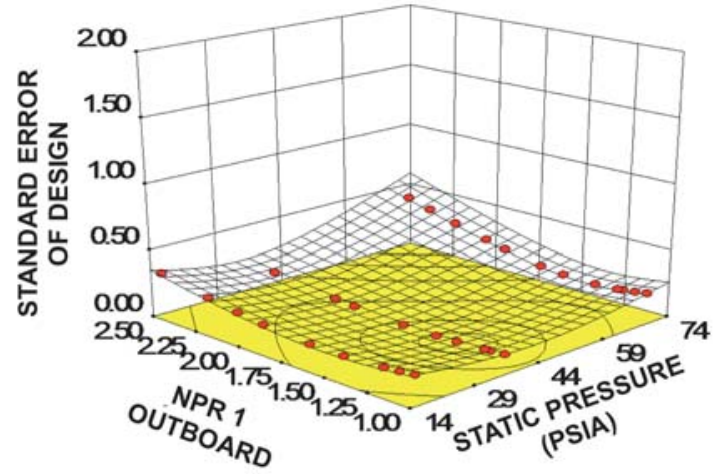

NPR2 $=1, N P R 3=1, N P R 4=1$

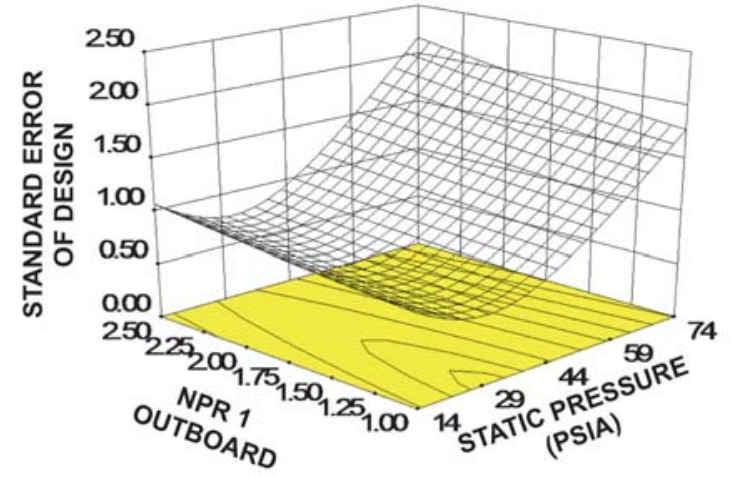

NPR2 $=2.5, \mathrm{NPR} 3=2.5, \mathrm{NPR} 4=2.5$

Figure 30. Standard error of prediction for the outboard flow path of the $60^{\circ}$ flap, $h / c=0.0022$ configuration

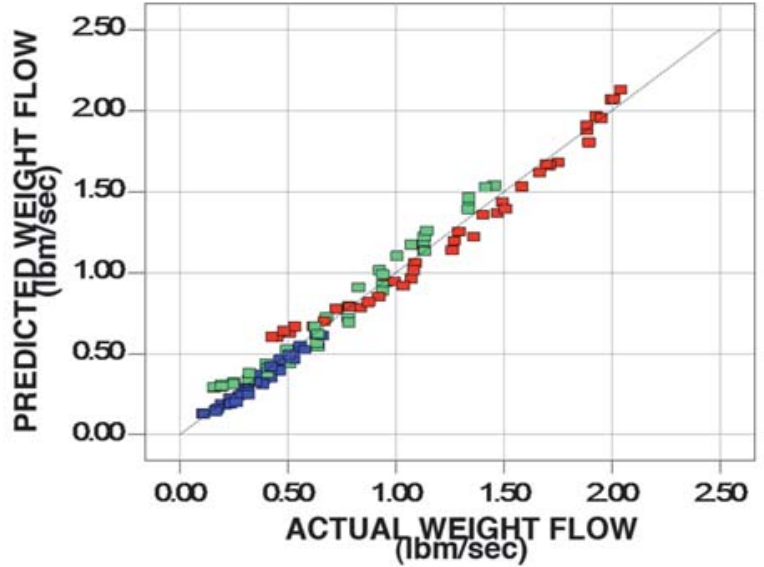

Figure 31. Quality of weight flow prediction for the $60^{\circ}$ flap, $h / c=0.0022$ configuration

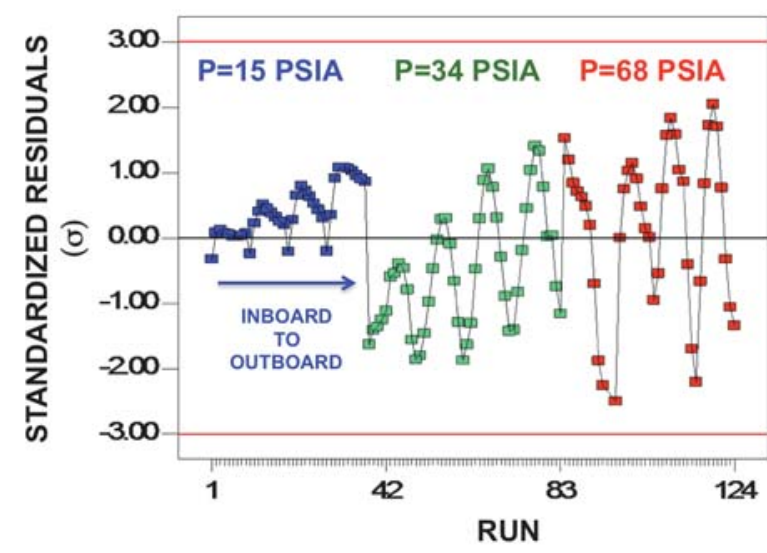

Figure 32. Standardized residuals for calibration of four independent flow paths for the $60^{\circ}$ flap, $\mathrm{h} / \mathrm{c}=\mathbf{0 . 0 0 2 2}$ configuration

The scatter in the measured data is reflected in the deviation from the predicted flow rate shown in Fig. 31. The standardized residuals shown in Fig. 32 illustrate that the error grows with increasing static pressure. The deviation also increases as the measurements move from the inboard to the outboard flow paths.

To verify this prediction model for the all-blowing configuration, a test case was evaluated using NPR $=1.9$ that were matched in all four flow paths for $\mathrm{Mach}=0.2$. The prediction model under-predicted the measured weight flow by $9 \%$. A portion of this bias error is associated with the effective area variation of the single flow path calibration that is not present when all flow paths are active. To achieve an estimated weight flow distribution using this technique it will be necessary to ratio the predictions with the total measured weight flow. 


\section{External Flow Path Evaluation}

This section discusses an investigation into the dramatic loss of lift for the high-lift configuration with a $60^{\circ}$ flap at Mach 0.2 shown in Fig. 3. The expected lift performance of the FAST-MAC model should follow the trends of the Mach 0.1 condition. As the momentum increases through the separation control region into the supercirculation region, the lift should continue to increase until the wing stalls. However, for the Mach 0.2 condition the lift peaked after transitioning to the super-circulation at a mean $\mathrm{C} \mu \sim 0.1$, then decreased for higher $\mathrm{C} \mu$ values. The following discussion will focus on the jet separation on the flap that relates to this lift performance.

\section{Two-Dimensional CFD Analysis}

To understand the physics associated with the lift loss at Mach 0.2, a two-dimensional CFD analysis was performed. The CFD simulations were performed using the Reynolds-averaged Navier-Stokes (RANS) structured mesh flow solver, OVERFLOW, developed by NASA ${ }^{30,31}$. The CFD simulations used the Spalart-Allmaras (SA) turbulence model with a rotational/curvature correction. The mesh had over one million grid points with a highresolution of points in the jet flow region, providing sufficient resolution of the complex flow physics on the flap (e.g., shocks and shock-boundary-layer separation). The geometry being investigated is a two-dimensional slice of the FAST-MAC model at a semi-span location of $y /(b / 2)=0.4$ aligned with the free-stream flow corresponding to a chord length of 19.8 inches and a slot height to chord ratio, $\mathrm{h} / \mathrm{c}$, of 0.0021 .

Results from the two-dimensional CFD analysis are shown in Fig. 33 for a sequence of increasing C $\mu$ values. The simulation with the lowest $\mathrm{C} \mu$ value of 0.037 shows the flow accelerating downstream of the slot exit with sonic region on the first flap radius. For this case the jet stays attached to the flap and is just beyond the transition into the super-circulation region. Increasing the blowing to a $\mathrm{C} \mu$ value of 0.071 results in the flow at the slot exit becoming sonic, as seen in the Mach contour plot in Fig. 33. The simulated Schlieren image reveals a shock at the slot exit followed by a series of diamond shocks. The diamond shocks are damped as the flow accelerates over the first flap radius. The Schlieren image for the $\mathrm{C} \mu 0.071$ case reveals a lambda shock near the beginning of the second flap radius, resulting in a thickening of the boundary layer. At a $\mathrm{C} \mu$ of 0.095 the flow separates at the beginning of the flap second radius and then reattaches to the flap. The Schlieren image shows a larger diamond shock structure with a stronger lambda shock at the separation point. Increasing $\mathrm{C} \mu$ to 0.108 results in a larger separated region and even stronger shocks. These two-dimensional CFD simulations suggest that the dramatic loss of lift at Mach 0.2 may be a result of a strong lambda shock that forms at the beginning of the flap second radius resulting in boundary layer separation on the flap thereby reducing the lift.

\section{Flap Boundary-Layer Measurements}

Two boundary-layer mini-rake probes were placed on the $60^{\circ}$ flap during the initial part of the wind tunnel test. The goals of the mini-rakes were to provide measurements of the jet magnitude and profile downstream of the slot for CFD verification and insight into the flow over the flap. While the CFD boundary conditions for the jet are NPR and jet total temperature, the slot exit velocity is dependent on the static pressure at the slot exit. As the lift increases, the static pressure will decrease at the slot exit, thus increasing the jet velocity. The mini-rakes will then provide valuable data about the jet magnitude and thickness, verifying that the CFD is matching the correct blowing conditions and evolution of the jet on the flap.

Fig. 34 shows a photo of the model with the mini-rakes on the $60^{\circ}$ flap. These two mini-rakes are located at 0.222 and 0.649 flap chords downstream from the jet exit. To reduce wind tunnel test time, these two measurements were made simultaneously by placing the mini-rakes at two different spanwise locations on the flap. The outboard mini-rake was at the 0.222 flap chord location while the inboard mini-rake was at 0.649 . Each mini-rake consisted of 15 total pressure probes of varying spacing with a total height of 0.45 inches.

The jet total pressure profiles are presented in Fig. 35, for varying blowing conditions at the two locations. To understand how the jet is spreading, the distance perpendicular to the surface is normalized by the slot height at the local span location. Figure 35 shows that the jet profile at the 0.222 flap chord location has expanded to two slot heights and the jet profile at 0.649 flap chord location has expanded to four slot heights. A comparison of the two jet profiles shows that the peaks of both jet profiles remain constant at one slot height from the surface. These data indicate that the jet remains attached at the probe locations for $0^{\circ}$ angle of attack and for all the blowing conditions and does not show shock-induced flow separation. 

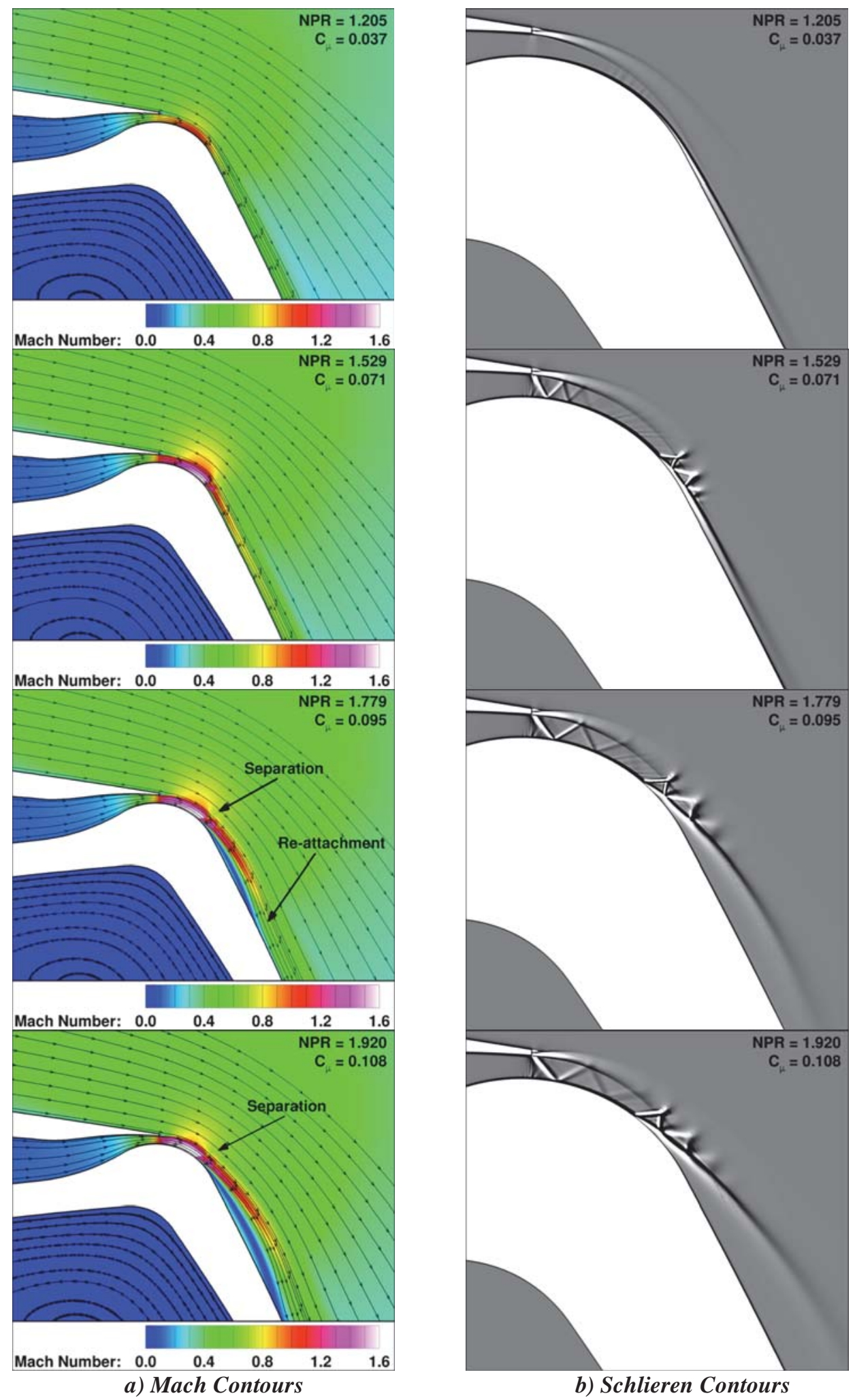

b) Schlieren Contours

Figure 33. 2D CFD simulation for $60^{\circ}$ flap configuration for varying blowing conditions; Mach=0.2, $\operatorname{Re}_{C}=10 \times 10^{6}, \alpha=0.0^{\circ}, h / c=0.0022$. 

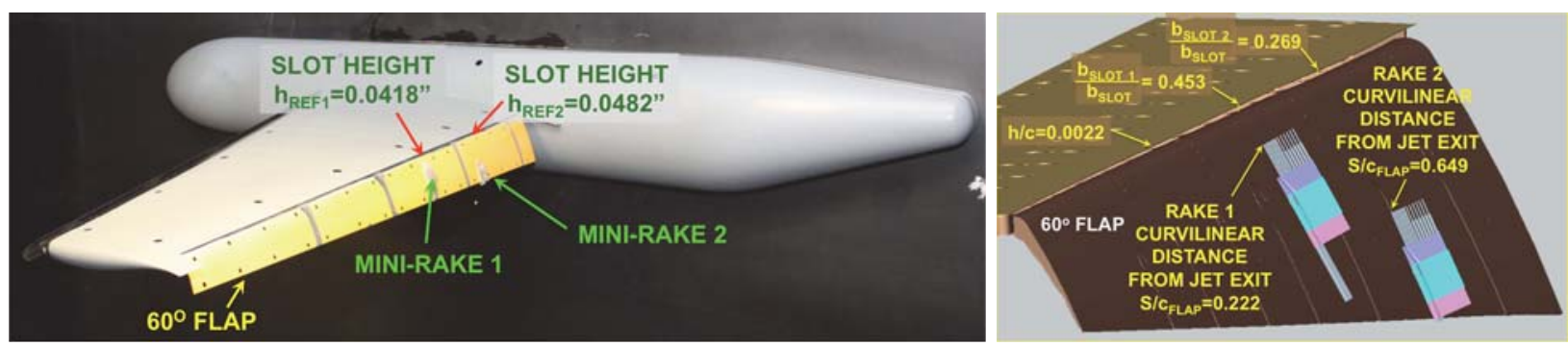

Figure 34. $60^{\circ}$ flap mini-rake configuration, $\mathrm{h} / \mathrm{c}=0.0022$

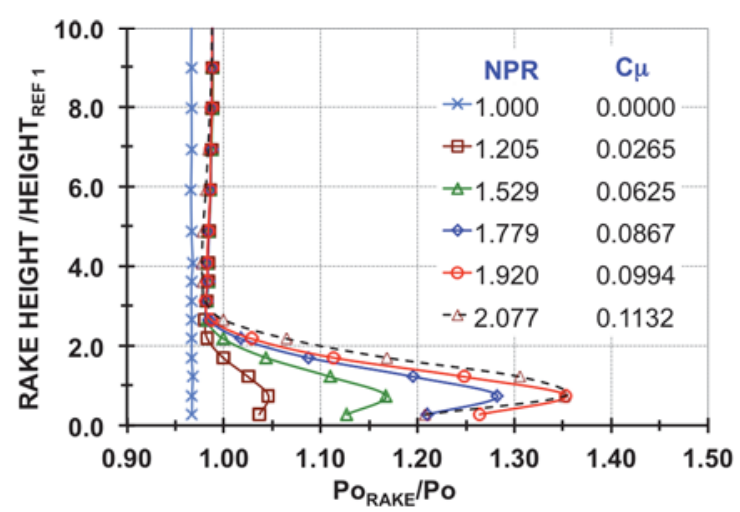

A) OUTBOARD RAKE

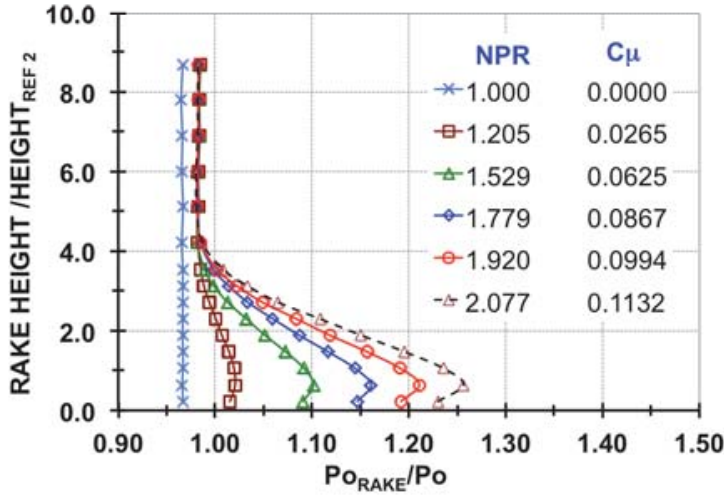

B) INBOARD RAKE

Figure 35. Mini-rake total pressure ratio profiles for the $60^{\circ}$ flap configuration, Mach $=0.20, \operatorname{Re}_{C}=10 \times 10^{6}$, $\alpha=0.0^{\circ}$, slot $h_{\text {REF } 1}=0.0418$ inch, slot $h_{\text {REF } 2}=0.0482$ inch, $h / c=0.0022$.

\section{Three-Dimensional CFD Analysis}

A preliminary three-dimensional simulation of the wind tunnel model has been performed using USM3D, an unstructured mesh flow solver code developed at NASA ${ }^{16}$. These data will highlight the interactions of the juncture and tip regions of the model with the blowing regions on the flap. Figure 36 shows the surface Cp contours and surface restricted streamlines on the $60^{\circ}$ flap for an NPR of 1.6 and 1.9 at $0^{\circ}$ angle of attack at Mach 0.2. The low blowing case has an NPR of $1.6(\mathrm{C} \mu=0.06)$ and shows attached flow on the flap. The NPR 1.9 case $(\mathrm{C} \mu=0.090$ shows incipient flow separation on the flap near the wing root and tip regions. Figure 36 also depicts the location of the two mini-rakes on the flap where the flow is still attached for the NPR 1.9 case. While these three-dimensional CFD simulations need further grid refinement, they indicate that the shock-induced flow separation initiates from the wing root and tip regions and is likely spread inward for higher blowing rates.

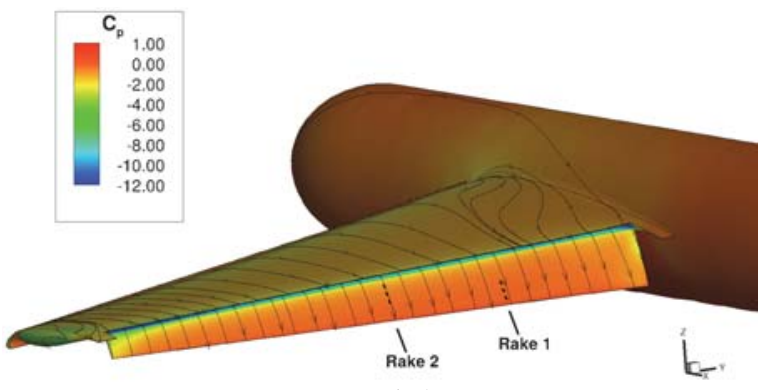

$N P R=1.6$

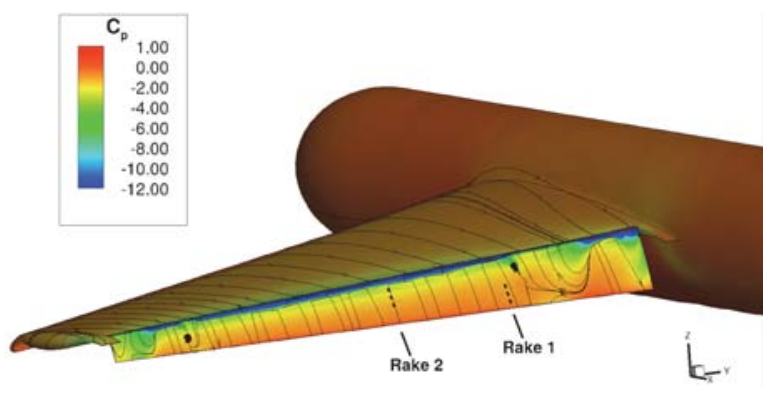

$N P R=1.9$

Figure 36. CFD simulation for the $60^{\circ}$ flap configuration highlighting the mini-rake locations and showing surface $C p$ contours and surface restricted streamlines. Mach $=0.20, \operatorname{Re}_{C}=10 \times 10^{6}, \alpha=0.0^{\circ}, h / c=0.0022$. 


\section{Concluding Remarks}

The focus of this paper has been on the development and characterization of the jet associated with the high Reynolds number testing of the FAST-MAC in the NASA Langley NTF. Initial testing revealed that there was a spanwise non-uniform flow at the jet exit that was linked to the perforated plates upstream of the model's settling chamber. These perforated plates were successfully re-designed resulting in uniform flow at the jet exit. This was considered a critical improvement necessary to achieve the maximum performance and to provide a uniform boundary condition for CFD.

A multiple-variable mathematical model was developed to describe the weight flow characteristics of each of the four flow paths. Error analysis of this model revealed that it was adequate for describing the single flow path configuration, but the errors grew with addition of flow paths. Therefore the model was used only as a guide for characterizing the tailored or partial span blowing and the distributed efficiency of the FAST-MAC nozzle. The air station MCV system provided the total weight flow for the all of the different blowing configurations.

The performance benefits of a smaller $\mathrm{h} / \mathrm{c}$ were also described as part of evaluating the FAST-MAC flow characteristics. A lift performance improvement was made by utilizing a smaller slot height, $\mathrm{h} / \mathrm{c}=0.0022$, as compared to the previously tested slot height of $h / c=0.0033$. CFD was used to provide insight into the flow physics associated with the degradation of the high-lift performance for a free stream Mach number of 0.2 that was not seen at a lower Mach number of 0.1. This loss of lift is believed to be a result of shock induced flow separation on the flap that is related to the aggressive $\mathrm{h} / \mathrm{r}_{1}$ and $\mathrm{r}_{2} / \mathrm{r}_{1}$ interface used in the FAST-MAC design. Incipient shock induced flow separation was predicted by two-dimensional CFD simulations that begins at a momentum coefficient of 0.1 (NPR 1.5) becoming more pronounced for higher values. The three-dimension CFD simulations are ongoing with additional grid refinment to better resolve the shocks downstream of the slot exit on the flap. However, the preliminary 3D simulations indicate that flow separation initiates from the wing root and tip regions and is likely spread inward for higher blowing rates.

\section{Acknowledgements}

The research has been supported by the Subsonic Fixed Wing project. Special thanks are given to Ruben Delrosario, Mike Rogers, Richard Wahls, Susan Wilz, Cathy McGinley, and Zac Applin for their continued support and encouragement. The successful second test of the FAST-MAC model could not have been accomplished without the dedication, technical expertise, and energy of the entire staff at the National Transonic Facility. Special appreciation is extended to Tom Hall for his expertise in building the miniature boundary layer rakes, and to Mark Cagle and Jarad Fell for their excellent oversight of the design and fabrication of the upgrades for the FAST-MAC model. Special gratitude is extended to the Chris Lynn of the National Force Measurement Technology Capability Office at NASA, and Modern Machine and Tool Inc., for their continued efforts in supporting the development of the NTF-117S semi-span balance system. 


\section{References}

1 Jones, G.S., Joslin, R.D., "Proceedings of the 2004 NASA/ONR Circulation Control Workshop", NASA/CP-2005213509, June 2005.

${ }^{2}$ Jameson, K.K, Marshal, D.D., Golden, R., Paciano, E., Englar, R.J., Gaeta, R.J., Paterson, J. Mason, D.,’Part1: The Wind Tunnel Model Design and Fabrication of Cal Poly' AMELIA 10 Foot Span Hybrid Wing-Body Low Noise CESTOL Aircraft,” AIAA Paper 2011-1306, January 2011.

${ }^{3}$ Zeune, C.H., "An Overview of the Air Force's Speed Agile Concept Demonstration Program," AIAA Paper 20131097, January 2013.

${ }^{4}$ Barberie, F.J., Wick, A.T., Hooker, J.R., Zeune, C.H., "Low Speed Powered Lift Testing of a Transonic Cruise Eficient STOL Military Transport,", AIAA Paper 2013,1099, January 2013.

${ }^{5}$ Harrison, N.A., Vassberg, J.C., DeHann, M.A., Gea, L.M., "The Design and Test of a Swept Wing Upper Surface Blowing (USB) Concept," AIAA paper 2013-1102, January 2013.

${ }^{6}$ Jones, G.S., Lin, J.C., Allan, B.G., Milholen, W.E., Rumsey, C.L., Swanson, R.C., "Overview of CFD Validation Experiments for Circulation Control Applications at NASA,” IPLC-London June 2008.

${ }^{7}$ Swanson, R.C., Rumsey, C.L., Anders, S.G., "Progress Towards Computational Methods for Circulation Control Airfoils,", AIAA Paper 2005-0089, January 2005.

${ }^{8}$ Wick, A.T., Hooker, J.R., Barberie, F.J., Zeune, C.H., "Powered Lift CFD Predictions of a Transonic Cruising STOL Military Transport,", AIAA Paper 2013-1098, January 2013.

${ }^{9}$ Englar, R. J., G. S. Jones, B. G. Allan, and J. C. Lin, "2-D Circulation Control Airfoil Benchmark Experiments Intended for CFD Code Validation,” AIAA Paper 2009-0902, January 2009.

${ }^{10}$ Milholen II, W.E., Jones, G.S., Chan, D.T., Goodliff, S.G., "High-Reynolds Number Circulation Control Testing in the National Transonic Facility (Invited)", AIAA paper 2012-0103, January 2012.

${ }^{11}$ Milholen II, W.E., Jones, G.S., and Cagle, C.M., "NASA High-Reynolds Number Circulation Control Research Overview of CFD and Planned Experiments (Invited)", AIAA Paper 2010-344, January 2010.

${ }^{12}$ Wahls, R.A., "The National Transonic Facility: A Research Retrospective (Invited)," AIAA Paper 2001-16587, January 2001.

${ }^{13}$ Jones, G.S., Milholen II, W.E., Goodliff, S.L., "Development of the Dual Aerodynamic Nozzle Model for the NTF Semi-Span Model Support System,”, AIAA Paper 2011- 3170, June 2011.

${ }^{14}$ Lynn, K.C., “Development of the NTF-117S Semi-Span Balance”, AIAA Paper 2010-4542, June 2010.

${ }^{15}$ Lynn, K.C., Rhew, R.D., Acheson, M.J., Jones, G.S., Milholen II, W.E., Goodliff, S.L., "High Reynolds Number Active Blowing Semi-Span Measurement System Development”, AIAA Paper 2012-3318, June 2012.

${ }^{16}$ Frink, N. T., "Tetrahedral Unstructured Navier-Stokes Method for Turbulent Flows," AIAA Journal, Vol. 36, No. 11, November 1998, pp. 1975-1982. 
${ }^{17}$ Campbell, Richard L, "Efficient Viscous Design of Realistic Aircraft Configurations (Invited)", AIAA Paper 982539, June 1998.

${ }^{18}$ Gatlin, G.M, Tomek, W.G., Payne, F.M., and Griffiths, R.C., "Recent Improvements in Semi-Span Testing at the National Transonic Facility (Invited)", AIAA Paper 2006-508, January 2006.

${ }^{19}$ Englar. R. J. and C. G. Huson. "Development of Advanced Circulation Control Wing High-Lift Airfoils," AIAA Paper 83-1847, July 1983. Also published in AIAA Journal of Aircraft. July 1984. pp.476-483.

${ }^{20}$ Englar, R.J., Smith, M.J., Kelley, S.M., and Rover, R.C., "Development of Circulation Control Technology for Application to Advanced Subsonic Transport Aircraft", AIAA Paper 93-0644, January 1993.

${ }^{21}$ Rogers, E.O., "Development of Compressible Flow Similarity Concepts for Circulation Control Airfoils", AIAA Paper 87-0153, January 1987.

${ }^{22}$ Abramson, J., Rogers, E.O., "High-Speed Characteristics of Circulation Control Airfoils”, AIAA Paper 83-0265, January 1983.

${ }^{23}$ Englar, R.J, Blaylock, G., Gaeta, RJ. Jones, G.S., Milholen II, W.E., "Recent Experimental Development of Circulation Control Airfoils and Pneumatic Systems,” AIAA Paper 2010-345, January 2010.

${ }^{24}$ Idelchik, I.E., Handbook of Hydraulic Resistance, $3^{\text {rd }}$ Edition, Hemisphere Publishing Corp, 1986.

${ }^{25}$ Cornell, W.G., "Losses in flow normal to plane screens, Trans. ASME, no.4, 45-53, 1958.

${ }^{26}$ Mentor Graphics, "Why is Engineering Fluid Dynamics (EFD) the Right Choice for CFD Analysis", FloEFDCFD whitepaper, 2007.

${ }^{27}$ Berrier, B.L., Leavitt, L.D., and Bangert, L.S., "Operating Characteristics of the Multiple Critical Venturi System and Secondary Calibration Nozzles Used for Weight-Flow Measurements in the Langley 16-Foot Transonic Tunnel," NASA TM 86405, 1985.

${ }^{28}$ Mikkelsen, K.L., Olstad, S.J.," Airflow Calibrations of NASA Langley Research Center Multiple Critical Venturi (MCV) Assemblies," FluiDyne Report 1835, June 1992.

${ }^{29}$ Montgomery, D., Design and Analysis of Experiments, John Wiley \& Sons, New York, 8th ed., 2013.

${ }^{30}$ Buning, P.G., Chiu, I.T., Obayashi, S., Rizk, Y.M., and Steger, J.L., "Numerical Simulation of the Integrated Space Shuttle Vehicle in Ascent," AIAA-88-4359, Aug. 1988.

${ }^{31}$ Renze, K.J., Buning, P.G., and Rajagopalan, R.G., "A Comparative Study of Turbulence Models for Overset Grids," AIAA-92-0437, Jan. 1992. 